\title{
Conifer Establishment and Encroachment on Subalpine Meadows around Mt. Baker, WA, USA
}

\author{
Ben Hagedorn ${ }^{1, *}$ and Aquila Flower ${ }^{2}$ \\ 1 Washington State Department of Natural Resources, Olympia, WA 98501, USA \\ 2 Environmental Studies Department, Western Washington University, 516 High St., \\ Bellingham, WA 98225, USA; flowera3@wwu.edu \\ * Correspondence: b.t.hagedorn@hotmail.com
}

Citation: Hagedorn, B.; Flower, A.

Conifer Establishment and

Encroachment on Subalpine Meadows around Mt. Baker, WA

USA. Forests 2021, 12, 1390. https:/ /

doi.org/10.3390/f12101390

Academic Editor: Pedro

Álvarez-Álvarez

Received: 13 August 2021

Accepted: 29 September 2021

Published: 12 October 2021

Publisher's Note: MDPI stays neutral with regard to jurisdictional claims in published maps and institutional affiliations.

Copyright: (c) 2021 by the authors. Licensee MDPI, Basel, Switzerland. This article is an open access article distributed under the terms and conditions of the Creative Commons Attribution (CC BY) license (https:// creativecommons.org/licenses/by/ $4.0 /)$.

\begin{abstract}
The subalpine ecotone is experiencing significant changes in habitat availability and connectivity as a result of climate change. The conversion of meadow habitats to forests has been observed in many mountainous regions. Rates of conifer encroachment into meadows appears to have increased in the 20th century, but the patterns of conifer establishment seem highly variable over both space and time. To understand how and why these changes vary temporally and spatially in the Pacific Northwest, we collected cross-sections and whorl counts from conifers along four transects in subalpine meadows around Mt. Baker, Washington. We quantified the relationships between temporal patterns of conifer establishment and a suite of climate variables, and between spatial patterns of conifer density and microsite characteristics. Our results show that establishment occurred in pulses throughout the 20th century, with greater establishment on drier sites during periods of greater precipitation, and greater establishment on wetter sites during periods of higher temperatures. We found that April precipitation and September temperature are particularly strongly correlated with establishment rates, suggesting that the best conditions for conifer seedling establishment occur in years with the warmth and soil moisture needed for the growing season to start earlier or last longer. Within individual meadows, conifer seedling establishment was greater on convex surfaces and in areas with a higher percentage of Vaccinium cover. Our findings at Mt. Baker show that periods of conifer establishment occurred somewhat synchronously across multiple mountains in the region, but we also identified distinct spatial and temporal differences linked to local site conditions.
\end{abstract}

Keywords: subalpine ecotone; mount baker; pacific northwest; cascade mountains; landscape ecology; biogeography

\section{Introduction}

Subalpine meadows play an important ecological role both within and beyond the subalpine ecotone. Many subalpine ecotones contain a patchy mosaic of relatively small, isolated meadows dominated by grasses, herbs, and shrubs within a larger matrix of forest. In western North America, such meadows are key summer feeding grounds for native cervids and bovids, and serve as the sole habitat for several endangered species and species sensitive to climate change [1-3]. Subalpine meadows store large amounts of snowmelt and release it slowly throughout the summer, which helps regulate stream flows in the Pacific Northwest $[1,4]$. The wildflowers in meadows also serve as a critical food source for pollinators [5]. In many subalpine ecosystems, treelines are moving upslope and trees are moving into previously treeless meadows as a result of warming temperatures [6]. The fragmentation and net loss of meadow habitat has a cascading effect throughout the ecosystem. A reduction in water storage capacity will lead to increased stream temperature and greater variability in stream flow, both of which are detrimental to salmon species $[4,7]$. The loss of forage and habitat can lead to increased stress on species that are already seeing significant declines, such as mountain goats and many pollinators $[6,8]$. 
The cascading effects of climate change on subalpine meadow ecosystems are still not well understood. Little is known about the spatial and temporal variability of changes occurring in western North America's subalpine meadows. Previous research has been conducted in only a few specific locations, primarily in national parks [9]. In Washington State, there have been several studies conducted on recent conifer encroachment in subalpine meadows and treeline advance around Mt. Rainier, but very few on other mountain peaks in the Cascade Mountains. The timing of conifer encroachment is variable across the Cascade Mountains, in part because the climatic controls on seedling establishment vary depending on local climatic conditions. Areas that are wetter tend to have more conifers establish when conditions are warmer and drier, and areas that are drier tend to have more conifer establishment when conditions are cooler and wetter [10-15]. Wetter areas tend to be on west facing slopes that receive increased precipitation due to orographic uplift or on north facing slopes that receive less solar radiation. Drier areas are often on south or east facing slopes, which get more solar radiation or are in a rain shadow. Microsite characteristics can lead to nearby areas having different temporal patterns of conifer establishment, even when these areas experience the same landscape-scale climate patterns $[10,12,15,16]$. Microsite characteristics also drive spatial patterns of establishment. Meadows throughout the region show patchy areas of establishment, with denser establishment on convex, more densely vegetated surfaces regardless of where in the meadow those areas occurred $[10,12,15]$.

Conifer encroachment has been studied in the southern Cascades and in coastal areas of Washington and British Columbia, but relatively little work has been done in the North Cascades. Previous studies have revealed intriguing commonalities and differences in landscape-scale and microsite-scale patterns of establishment throughout the region, but the limited spatial coverage of these studies hampers a full understanding of the causal mechanisms producing spatial and temporal variability in conifer encroachment. Our study applies newer methods to update and expand the research around Mt. Baker and answer the following questions:

1. What is the relationship between temporal patterns of conifer establishment and variability in temperature, precipitation, and snowpack?

2. What is the relationship between spatial patterns of conifer establishment and spatial variation in microtopography and plant cover?

3. How similar are the patterns of conifer encroachment and establishment at Mt. Baker to patterns of establishment and encroachment in other parts of the Washington Cascades?

\section{Materials and Methods}

\subsection{Study Area}

Mt. Baker is a heavily glaciated stratovolcano in the North Cascades of Washington State (Figure 1). Glaciers on Mt. Baker advanced and retreated throughout the late Pleitocene and Holocene, with the most recent maximum extent occurring during the mid-1800s [17]. Subalpine meadows occur on variable terrain created by older glaciations. Our sites sit below glacial moraines (Figure A1), well as at the heads of glacially eroded valleys (Figure A2). The steep terrain and unconsolidated substrate are prone to mass wasting events (Figure A3), which leaves disturbed areas of uneven topography below treeline (Figure A4). These disturbances are what form the subalpine meadows comprised of mainly shrubs and herbaceous plants. The soils underlying these meadows have a base of diamicton, followed by volcanic tephra, silt, sand, and sandy to muddy peat [17].

The subalpine meadows on Mt. Baker experience warm, dry summers and cool, wet winters, on the boundary between two Koppen Climate Classifications: Warm Summer Mediterranean and Temperate Oceanic [18] (Figure 2). Cool, wet winters produce a large amount of snowfall. Mt. Baker Ski Area averaged $1581 \mathrm{~cm}$ of snow per season from 1971 through 2000 and holds the record for most snowfall in snowfall season, totaling $2850 \mathrm{~cm}$ from July 1998 to June 1999 [19]. 


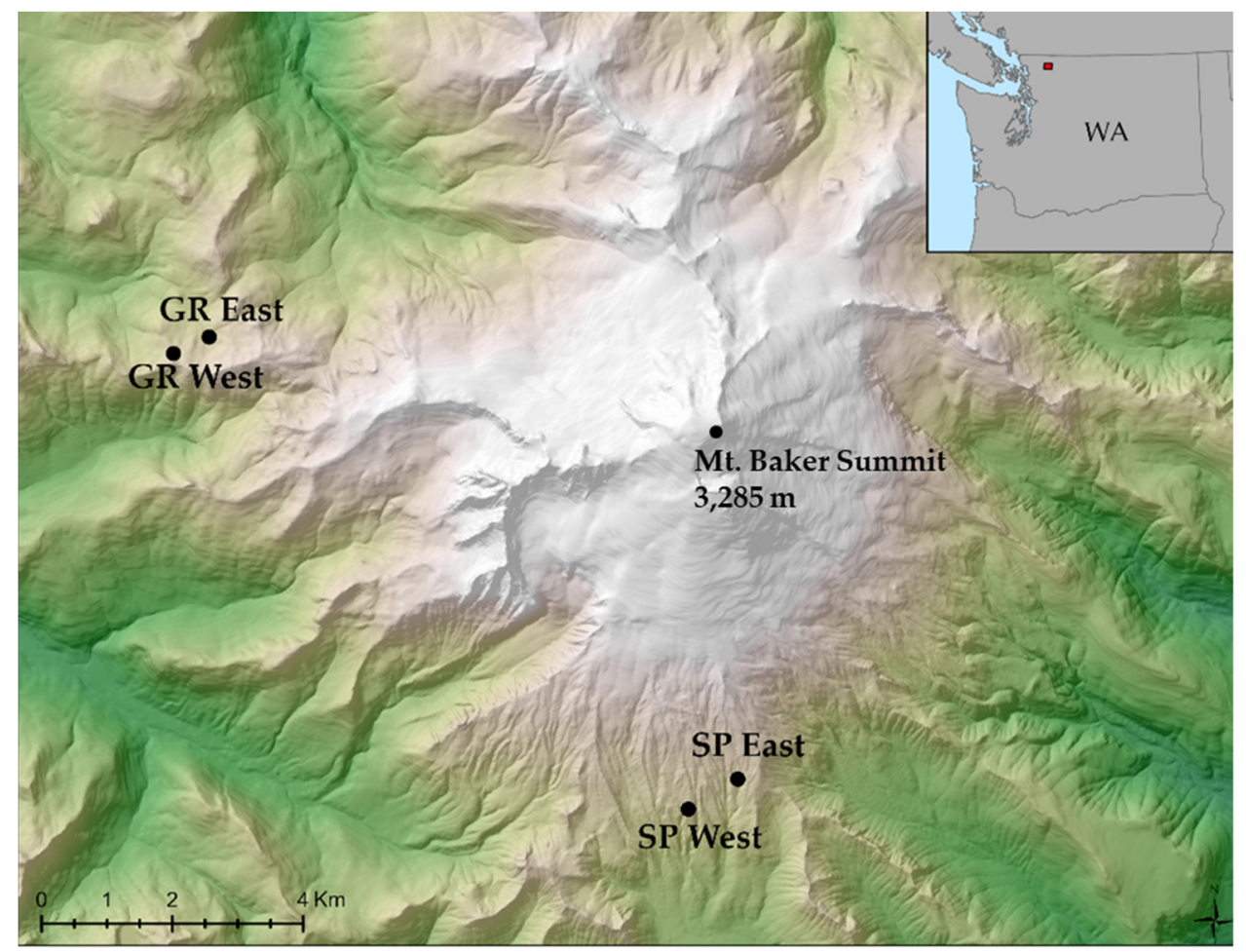

Figure 1. Study site locations. The two transects along the Scott Paul (SP) Trail are both south facing, and the two transects on Grouse Ridge (GR) are both north Facing.

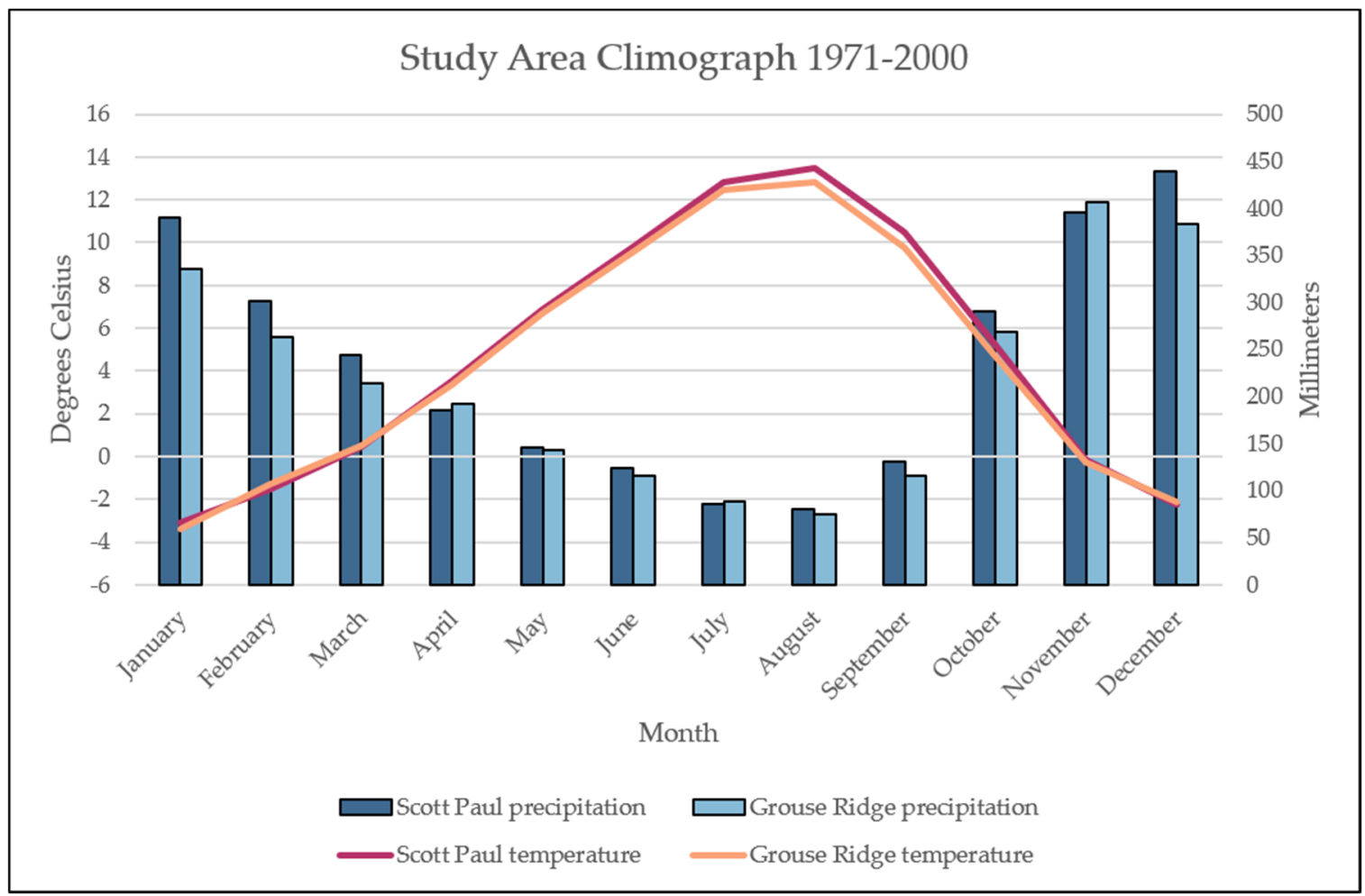

Figure 2. Climograph with precipitation and temperature for both the Scott Paul and Grouse Ridge site.

Trees and other plants growing in the subalpine ecotone are adapted to these cold, wet winter conditions and relatively young soils. The most common tree species at our sites are mountain hemlock (Tsuga mertensiana), Pacific silver fir (Abies amabilis), and, at the Grouse Ridge site, Alaskan yellow cedar (Callitropsis nootkatensis). Pacific silver fir 
tends to be more shade tolerant than mountain hemlock, while mountain hemlock tends to be more tolerant of colder temperatures, and both have similar tolerances to snowpack depth and soil moisture [11,20]. Yellow cedar is more drought tolerant than other tree species in this ecosystem. Under most conditions within the meadows, yellow cedar is out-competed by faster-growing Pacific silver fir and mountain hemlock which specialize in growing in cold and wet environments. However, on drier microsites yellow cedar can outcompete silver fir and mountain hemlock [21,22]. The majority of low-growing meadow plants at our study sites belong to two genera of the Ericaceae family: Vaccinium and Phyllodoce. Common species include pink mountain-heather (Phyllodoce empetriformis), yellow mountain-heather (Phyllodoce glanduliflora), black huckleberry (Vaccinium membranaceum), and dwarf bilberry (Vaccinium caespitosum). Other notable species are White-flowered rhododendron (Rhododendron albiflorum) and arctic lupine (Lupinus arcticus).

\subsection{Field Methods}

We collected samples at two sites with two transects per site. One site was on a north-facing slope, the other a south-facing slope (Figure 1). All transects were at a similar elevation, with a maximum difference in elevation of $39 \mathrm{~m}$ (Table 1). Each of our four transects was $50 \mathrm{~m}$ long and two meters wide. Each transect started near a stand of mature trees that could act as a potential seed source, and then crossed the meadows from east to west, maintaining a consistent elevation across the slope. We delineated a continuous grid of square meter plots on either side of the transect and recorded plot characteristics and tree measurements in each plot.

Table 1. Coordinates and elevation for each transect.

\begin{tabular}{cccc}
\hline Site ID & Latitude & Longitude & Elevation (Meters) \\
\hline SP West & $48.72416 \mathrm{~N}$ & $121.822 \mathrm{~W}$ & 1489 \\
\hline SP East & $48.72833 \mathrm{~N}$ & $121.812 \mathrm{~W}$ & 1528 \\
\hline GR West & $48.78807 \mathrm{~N}$ & $121.926 \mathrm{~W}$ & 1500 \\
\hline GR East & $48.78975 \mathrm{~N}$ & $121.921 \mathrm{~W}$ & 1521 \\
\hline
\end{tabular}

Our transects were located in meadows likely created through a combination of mass wasting events that created localized depressions, and persistent snowpack that limit the establishment of trees. Indigenous peoples have traditionally used fire as a tool for maintaining culturally desirable vegetation characteristics, such as abundant huckleberry production, in subalpine ecosystems along the Cascade Mountains [23]. However, we found no evidence of recent burning, such as charcoal, nor did we find historical records of Indigenous burning in this particular location.

For every plot, we determined whether the relative local microtopographic position of the plot was concave or convex. The meadows are comprised of both convex and concave features caused by various mass wasting or other erosional processes. If a plot was located on a convex feature in relationship to the topography of the meadow, then that plot was defined as convex. We also estimated the percent of the ground covered by the three most abundant and dominant genera of shrubs at our sites: Phyllodoce, Lupinus, and Vaccinium.

In addition to the plot level data, we collected measurements from every tree along each transect. We recorded the species and basal diameter for each tree, and we recorded the height of trees when the top of the tree was within arm's reach. We also recorded the diameter at breast height for all trees with a height greater than $1.37 \mathrm{~m}$. We collected cross-sections in alternating plots along the transect. We cut the trees as close to the root collar as possible, sometimes digging with a shovel, taking care to cut perpendicular to the direction of growth. For trees under one centimeter in basal diameter, we counted whorls instead of cutting a cross-section to get an estimate of age [24]. 


\subsection{Lab Methods}

We sequentially sanded cross-sections with a belt sander, using 150-, 220-, and 320-grit sandpaper. We then hand-sanded samples with 400- and 600-grit sandpaper in order to clearly see individual cells under a microscope. Once sanded, we counted the rings under a dissecting microscope to determine the establishment date of each sample using the Yamaguchi list method for visual cross dating [25]. We then measured ring widths using a Velmex Unislide and statistically cross-dated samples greater than 50 years old using COFECHA [26,27]. Samples with low inter-series correlations or identifiable dating inaccuracies were measured again and corrected if necessary.

\subsection{Statistical Methods}

All climate data used for this study are PRISM data statistically downscaled using ClimateWNA [28-30] for the years 1901-2010, as there are no suitable SNOTEL or weather stations near the study area. Snowpack and snowfall data were derived from a monthly water balance model using PRISM data [31] for the years 1950-2010. This model specifically performs well along the Pacific coast, simulating snowpack with a bias of $+/-50 \mathrm{~mm}$ at $68 \%$ of 713 SNOTEL sites [31]. To address potential errors in temporal accuracy of tree establishment dates, we grouped our establishment dates into five-year bins, and we averaged climate data into the same five-year bins.

To answer our research question "what is the relationship between temporal patterns of conifer establishment and variability in temperature, precipitation, and snowpack?", we tested for relationships between the number of trees established in each five-year bin and climate variables averaged for the same five-year period using a series of Kendall's correlation analyses (Table 2). Partial correlation analysis is useful when multiple variables have known relationships with each other, such as the relationship between temperature and precipitation, that may confound their apparent correlation with a third variable (Figure A5 and Table A1). We used Kendall's correlations because our data were neither homoscedastic nor normally distributed (Tables A2 and A3). For all statistical tests we used a significance level of 0.05 .

Table 2. Climate variables used in partial correlation analyses with number of trees established in each 5-year bin. The growing season is defined as the months of May through September.

\begin{tabular}{c}
\hline Climate Variables-Partial Correlation with Establishment Bin \\
\hline Mean annual temperature (MAT) controlled for mean annual precipitation \\
\hline Mean annual precipitation (MAP) controlled for mean annual temperature \\
\hline Mean growing season temperature (MGST) controlled for mean growing season precipitation \\
\hline Mean growing season precipitation (MGSP) controlled for mean growing season temperature \\
\hline Mean water year temperature (MWYT) controlled for mean water year precipitation \\
\hline Mean water year precipitation (MWYP) controlled for mean water year temperature \\
\hline Mean monthly temperatures controlled for monthly precipitation \\
\hline Mean monthly precipitation controlled for monthly temperature \\
\hline March-July monthly snowpack depth controlled for monthly temperature and precipitation \\
\hline April, May snowfall controlled for monthly temperature and precipitation \\
\hline Number of frost-free days (NFFD) controlled for mean growing season precipitation \\
\hline
\end{tabular}

To answer our research question "what is the relationship between spatial patterns of conifer establishment and spatial variation in microtopography and plant cover?", we used non-parametric tests to assess the relationship between conifer stem density and spatial site characteristic variables. We used the Wilcoxon rank sum test to determine whether 
there was significantly greater stem density in either convex or concave plots, and we used Kendall's correlation analyses to determine if there was a relationship between stem density and Phyllodoce cover, Vaccinium cover, total vegetation cover, and the distance from seed source (Table 3). When testing the relationship between stem density and distance from seed source, we also performed the test with just the stem density in only convex plots to eliminate any potential influence that microtopography might have.

Table 3. Variables used to test relationships between conifer stem density and microsite characteristics within meadows.

\begin{tabular}{c}
\hline Spatial Variables-Evaluated with Stem Density \\
\hline Microtopographic position \\
\hline Percent vaccinium cover \\
\hline Percent heather cover \\
\hline Percent vegetation cover \\
\hline Distance from seed source
\end{tabular}

Finally, we tested for relationships between the age and spatial distribution of trees, as well as age and growth characteristics of trees (Table 4). We used the Wilcoxon rank sum test to determine whether trees were significantly older in concave or convex plots, and used Kendall's correlations to determine if there was a relationship between the age of trees and the distance from seed source. We also used Kendall's correlations to determine if there was a relationship between tree age and basal diameter as well as age and height. We used a logarithmic transformation on tree heights and basal diameters due to a trend in the residuals (Figure A6).

Table 4. Variables used to test relationships in the age of trees. The variables include both spatial and growth variables of trees.

\begin{tabular}{c}
\hline Ecological Variables-Evaluated with Tree Age \\
\hline Microtopographic position \\
\hline Distance from seed source \\
\hline Tree height (log transformation) \\
\hline Tree basal diameter (log transformation)
\end{tabular}

\section{Results}

We collected samples from and determined the ages of 130 mountain hemlock, 65 Pacific silver fir, and 16 Alaska yellow cedar trees, saplings, and seedlings. We were able to successfully crossdate our series using a combination of visual and statistical crossdating (Table 5). However, our mean interseries correlations are very low (Table 5). These low interseries correlations are attributable to a high degree of spatial variability in microsite conditions and pervasive reaction wood in most samples caused by repeat snow events bending small saplings.

\subsection{Establishment Pulses}

When looking at the temporal patterns of establishment for all transects combined, there are clear pulses in establishment (Figure 3). An establishment pulse is a term commonly used in encroachment research that lacks a precise definition and is typically based on a subjective, visual assessment. Here it is used to mean a period of time in which there is generally a greater number of seedlings established than in the preceding and following years. The first pulse starts in 1926-1930 and ends in 1956-1960. The second pulse starts in 1981-1985 and continues until 2011-2015. The pulses for the individual species are slightly 
different, but they follow the same general pattern with the exception of yellow cedar, which has no obvious pulses of establishment (Figure 4). Mountain hemlock has establishment pulses from 1926-1930 to 1956-1960 and again from 1981-1985 to 2006-2010. Silver fir has pulses of establishment from 1941-1945 to 1951-1955 and again from 1991-1995 to 2011-2015.

Table 5. The number of samples dated by each dating method, mean interseries ring-width correlations, and mean sensitivity of ring-width indices for each species at each transect, all species combined at each transect, and each species at all transects combined. Species include Tsuga mertensiana (TSME), Abies amabilis (ABAM), and Callitropsis nootkatensis (CANO).

\begin{tabular}{|c|c|c|c|c|c|}
\hline & All Transects & Scott Paul West & Scott Paul East & Grouse Ridge West & Grouse Ridge East \\
\hline Statistically Crossdated & 37 & 14 & 5 & 10 & 8 \\
\hline Visually Crossdated & 84 & 37 & 16 & 18 & 13 \\
\hline Whorl Counted & 90 & 12 & 42 & 35 & 1 \\
\hline All species R-value & 0.178 & 0.208 & 0.113 & 0.11 & 0.128 \\
\hline TSME R-value & 0.18 & 0.212 & 0.113 & 0.159 & 0.059 \\
\hline ABAM R-value & 0.095 & 0.126 & NA & 0.038 & NA \\
\hline CANO R-value & 0.148 & NA & NA & 0.24 & 0.145 \\
\hline $\begin{array}{l}\text { All species mean } \\
\text { sensitivity }\end{array}$ & 0.408 & 0.408 & 0.459 & 0.381 & 0.4 \\
\hline TSME mean sensitivity & 0.419 & 0.412 & 0.408 & 0.399 & 0.42 \\
\hline ABAM mean sensitivity & 0.395 & 0.421 & NA & 0.383 & NA \\
\hline CANO mean sensitivity & 0.358 & NA & NA & 0.325 & 0.368 \\
\hline
\end{tabular}

The individual transects show pulses of establishment, except for Grouse Ridge East. Pulses at the remaining transects may not exactly replicate the pulses from the combined data, but they do all have similarities to the overall trend. Scott Paul West and Grouse Ridge West both show two pulses: one centered in the 1940s and 1950s and another centered in the 2000s. Scott Paul east shows the pulse in the 2000s, but it doesn't show any pulse earlier in the 20th century.

\subsection{Climate Relationships}

Studying annual and seasonal climate variables at the site level shows the differing climate relationships at both sites. There are small, but ecologically important differences in temperature, precipitation (Figure 2), and snowpack (Figure A7) between the Scott Paul and Grouse Ridge sites and these create differences in the limiting factors that inhibit conifer establishment. Conifer establishment at Scott Paul tends to be more temperature driven, with strong positive relationships for both annual and growing season temperature (Figure 5). Conifer establishment at Grouse Ridge is more precipitation driven with a strong positive relationship for mean annual precipitation. There is little difference in these relationships between the different species (tree species correlations can be seen in Figures A8-A17 in Appendix A). These relationships remain consistent when viewing the normal Kendall's correlations as opposed to the partial Kendall's correlations (Figures A18-A27 in Appendix A). 


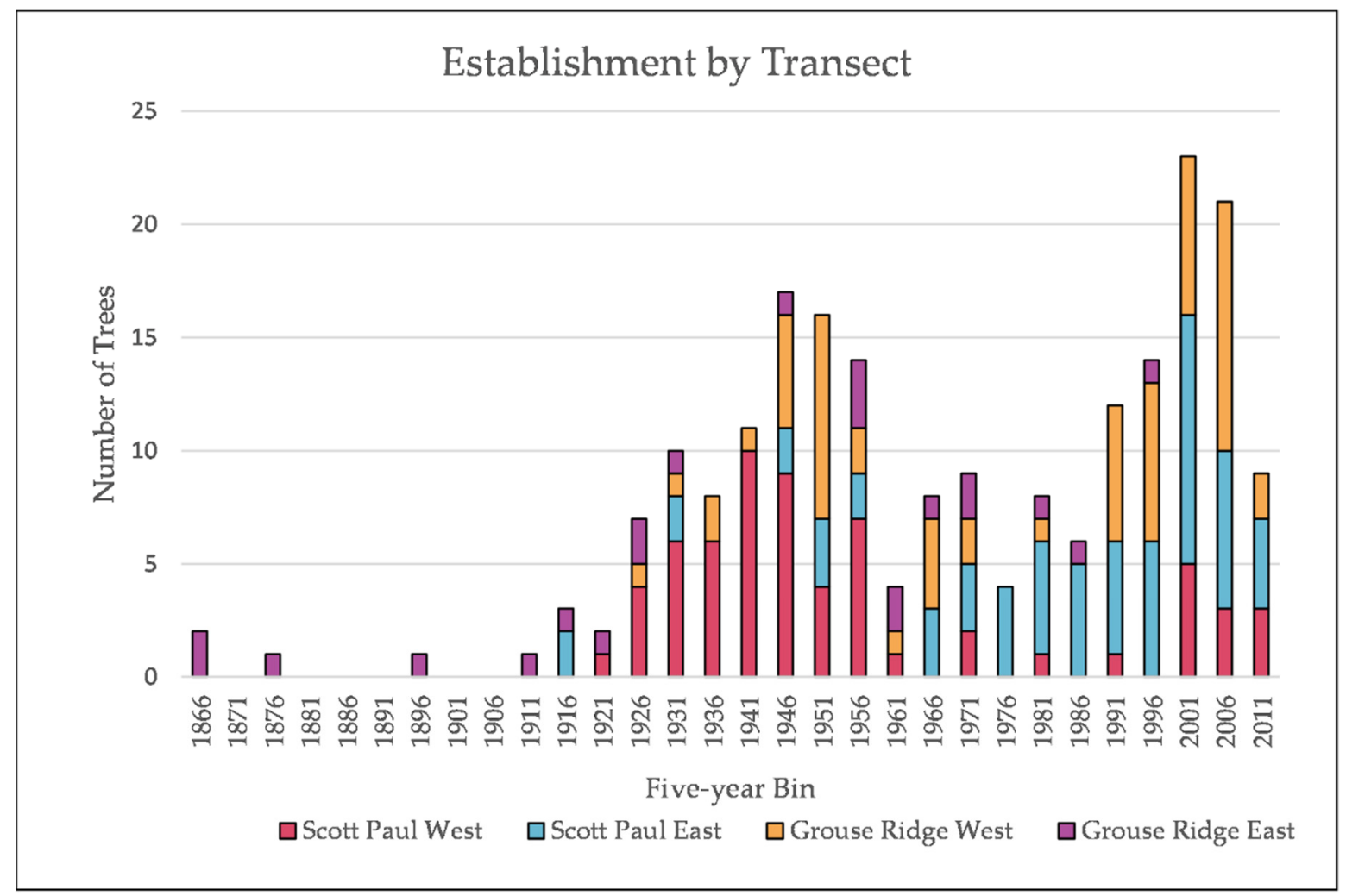

Figure 3. The number of trees established in each five-year bin at each transect. The dates on the graph are the start dates of each five-year bin.

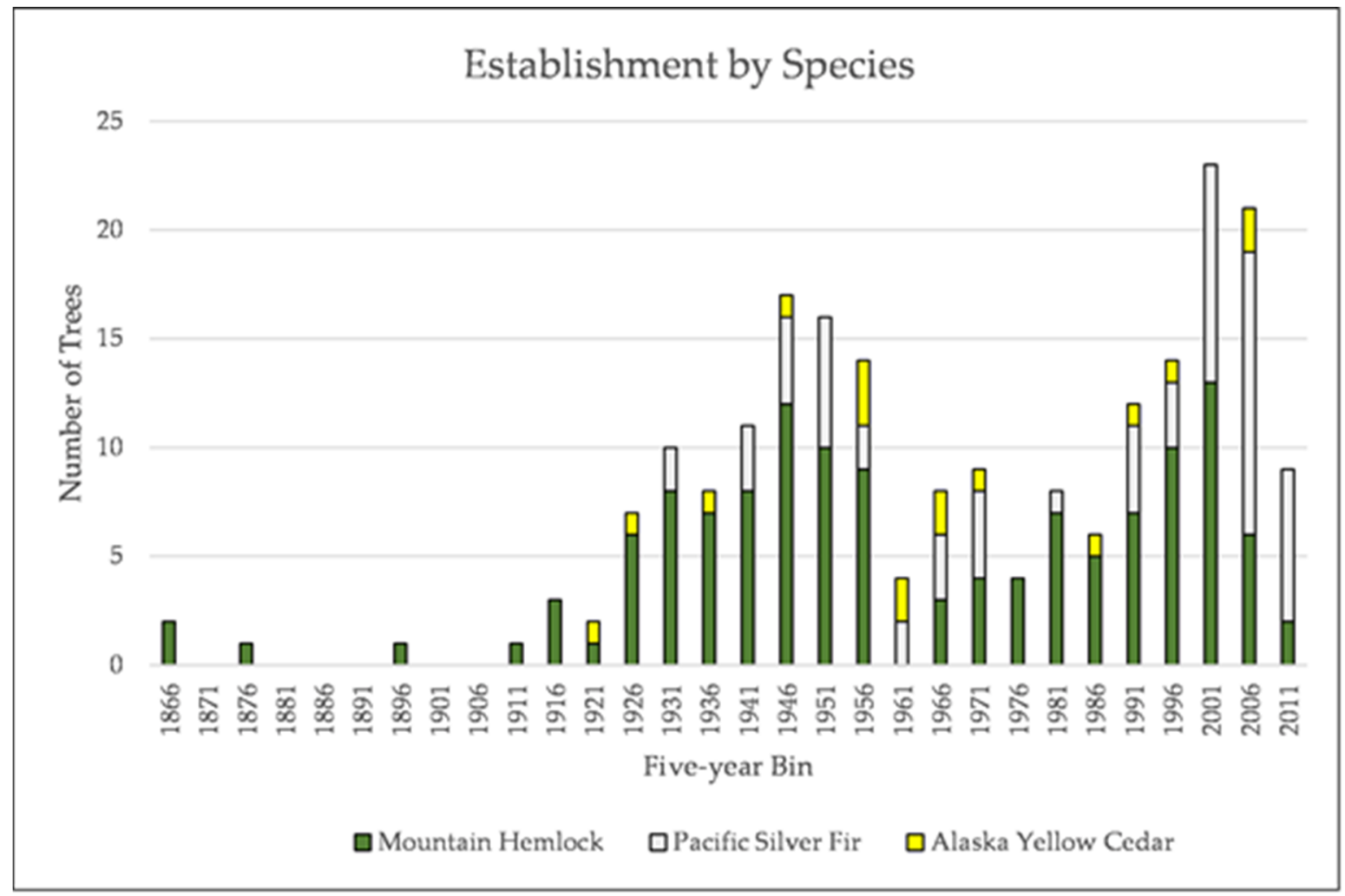

Figure 4. Total number of trees of each species that established in each five-year establishment bin for all the transects combined. The dates on the graph are the start dates of each five-year bin. 


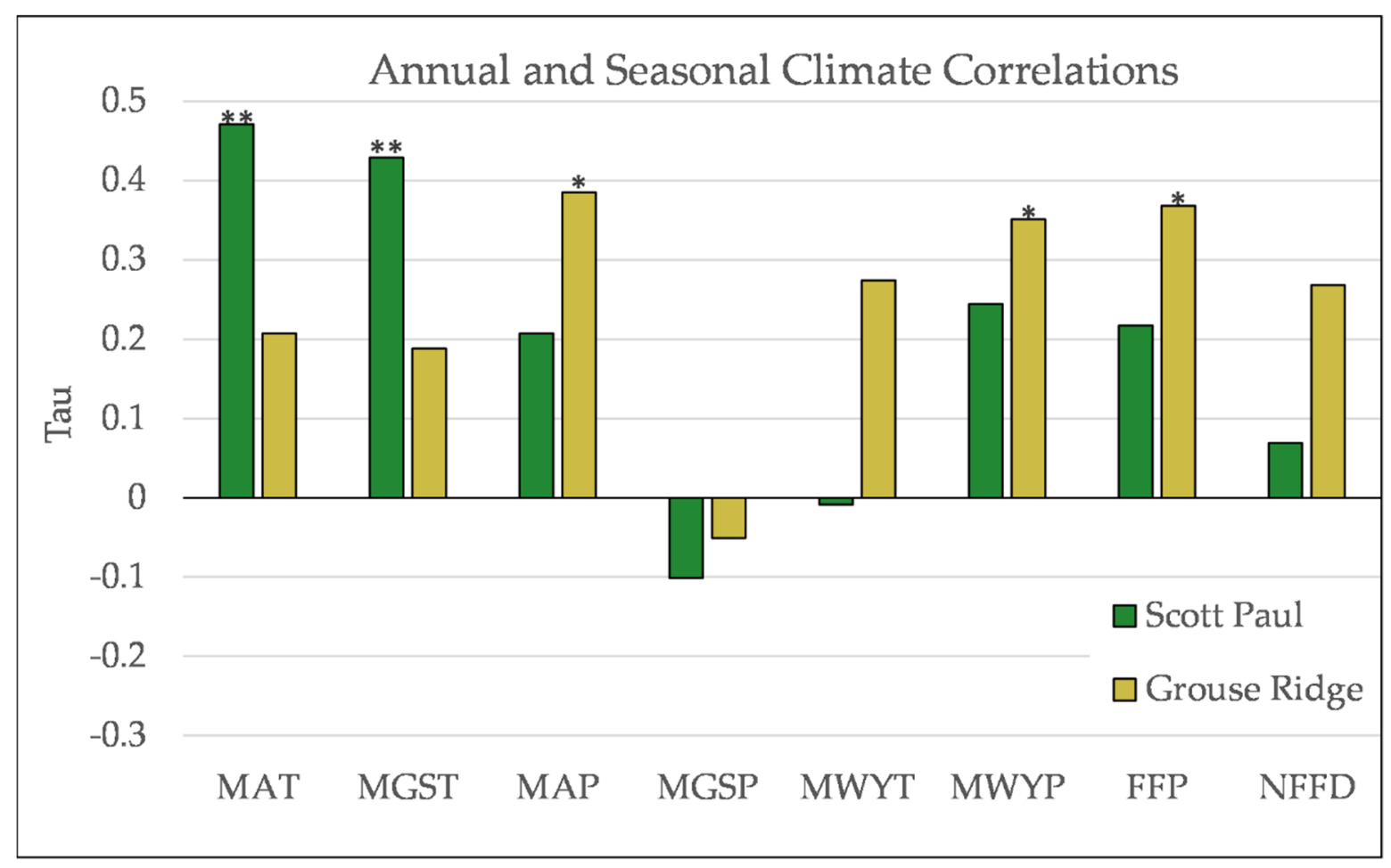

Figure 5. Tau values for partial Kendall's correlations between climate variables and tree establishment in five-year establishment bins for both sites. ${ }^{*}=p$-value $<0.05,{ }^{* *}=p$-value $<0.01$. Mean Annual Temperature (MAT), Mean Growing Season Temperature (MGST), Mean Annual Precipitation (MAP), Mean Growing Season Precipitation (MGSP), Mean Water Year Temperature (MWYT), Mean Water Year Precipitation (MWYP), Frost Free Period (FFP), and Number of Frost Free Days (NFFD).

The monthly variables show consistent patterns in differences between the Scott Paul and Grouse Ridge Sites, but also highlight some key similarities. Scott Paul has a consistent positive relationship between establishment and mean monthly temperature. The strongest and most significant relationship is between establishment and September mean temperature (Figure 6). Grouse ridge has a much more inconsistent and generally weaker correlation between establishment and mean monthly temperature, but the strongest relationship there is also in September. For monthly precipitation, Scott Paul has weaker, less consistent correlations (Figure 7), and Grouse Ridge has stronger consistently positive correlations. For both sites, there was a strong positive correlation is in April, followed by the strongest negative correlation in May. The pattern of consistent positive correlations for monthly temperature at Scott Paul and precipitation at Grouse Ridge matches the pattern observed in the seasonal and annual variables, but gives more detail about how weather patterns in specific parts of the year or season can have a stronger impact on establishment.

When looking at the relationship between establishment and snow variables, we once again see that the transition from April to May is critical for establishment at both sites (Figure 8). There is a sharp reduction in the strength of the correlation between snowfall and establishment at both sites as we go from April to May. We also analyzed snowpack, as opposed to snowfall, and found consistently positive, weak, not statistically significant relationships between establishment and monthly snowpack from March through July (Figure 9). 


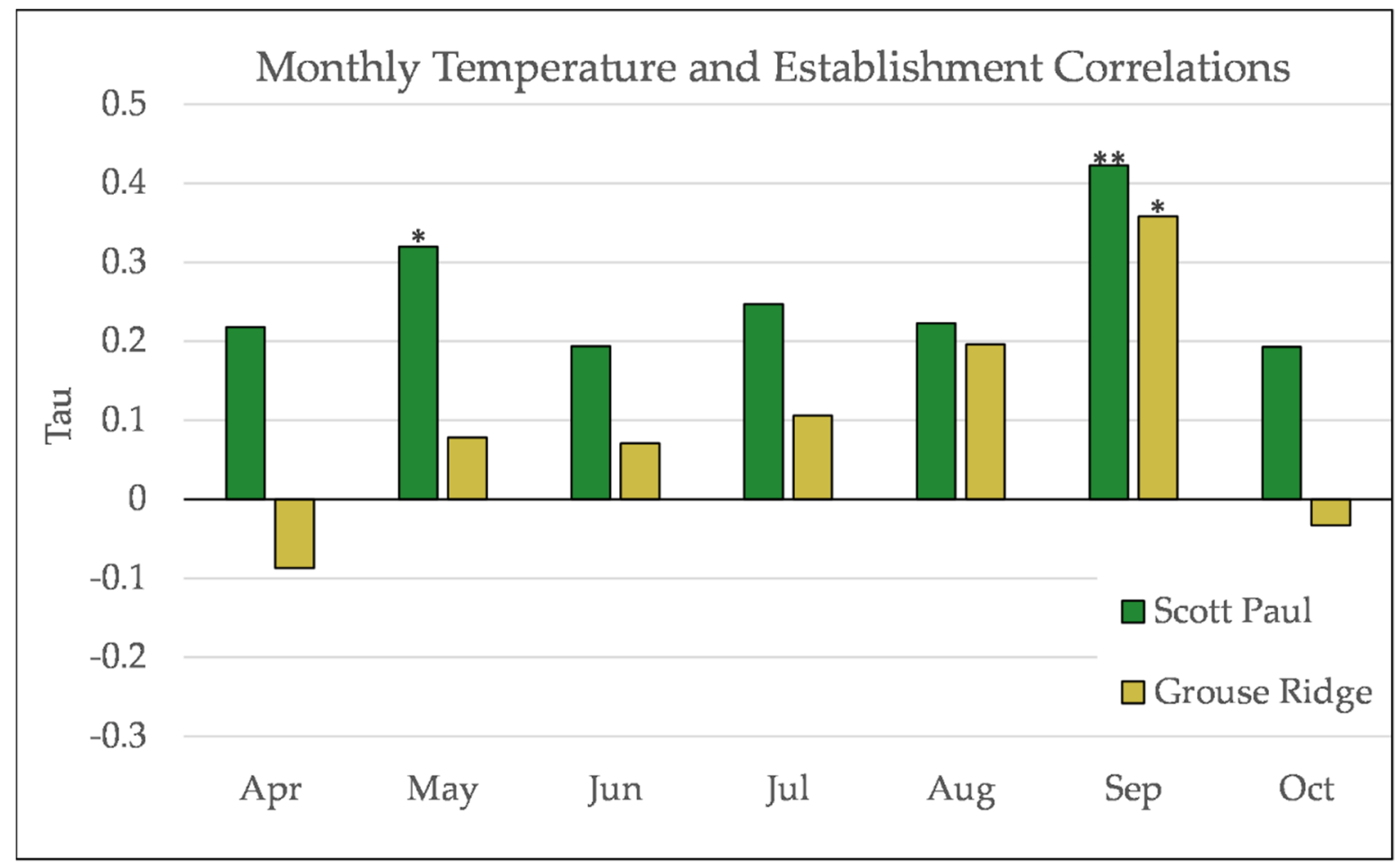

Figure 6. Partial Kendall's correlation between mean monthly temperature and establishment at both sites. ${ }^{*}=p$-value $<0.05$, ${ }^{* *}=p$-value $<0.01$.

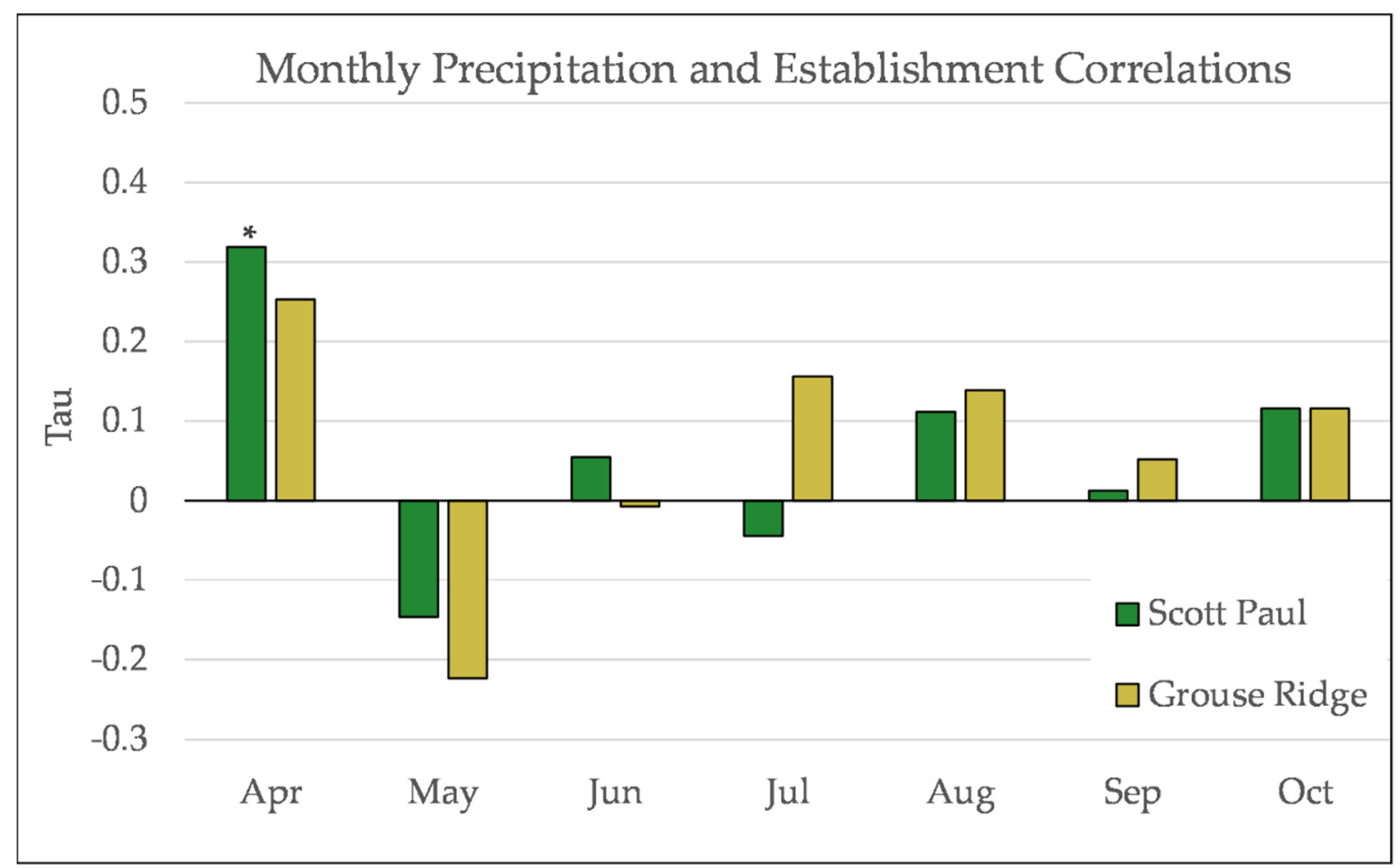

Figure 7. Partial Kendall's correlation between mean monthly precipitation and establishment at the both sites. $*$ *value $<0.05$. 


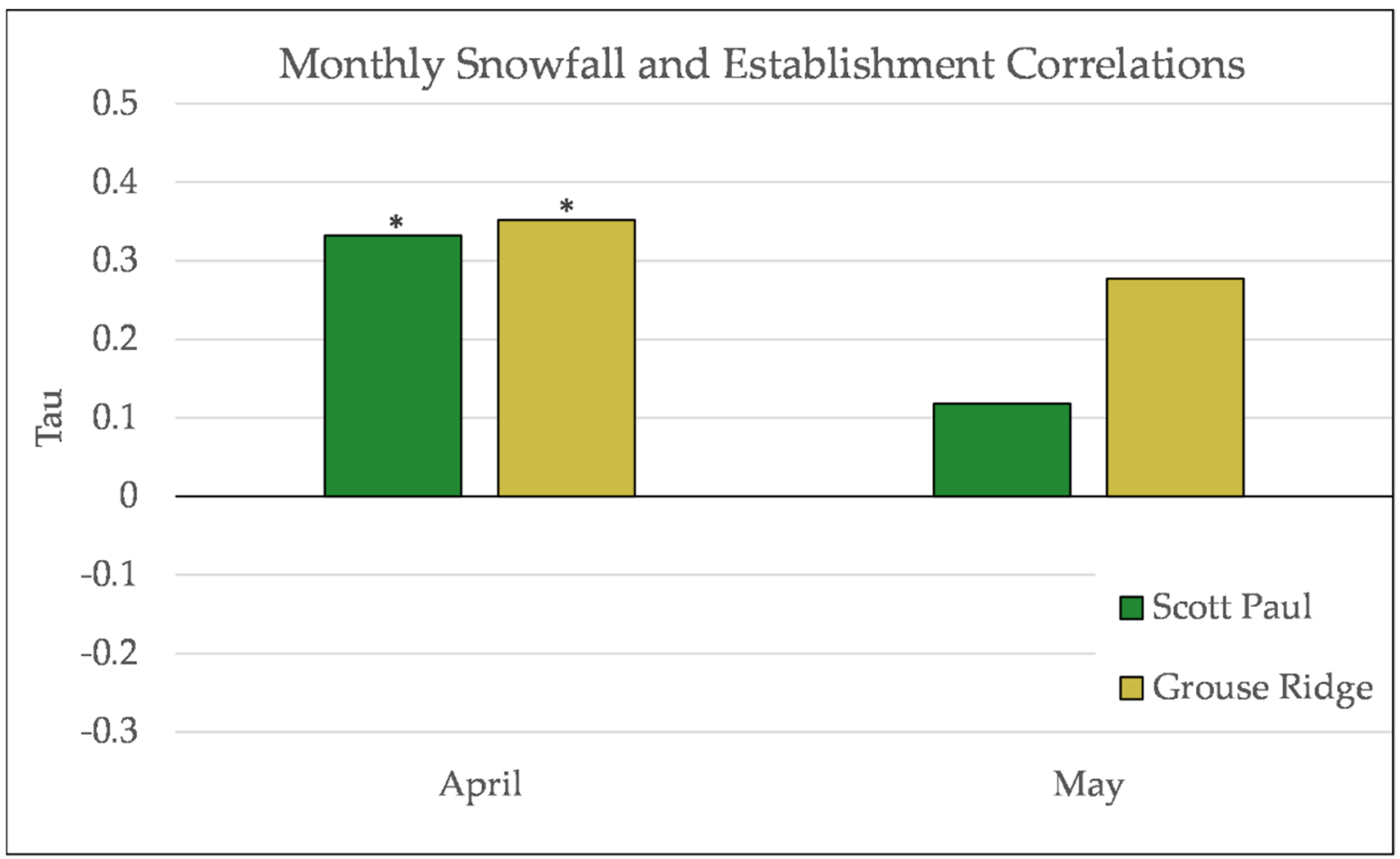

Figure 8. Partial Kendall's correlation controlled for temperature between mean monthly snowpack and establishment at both sites. ${ }^{*}=p$-value $<0.05$.

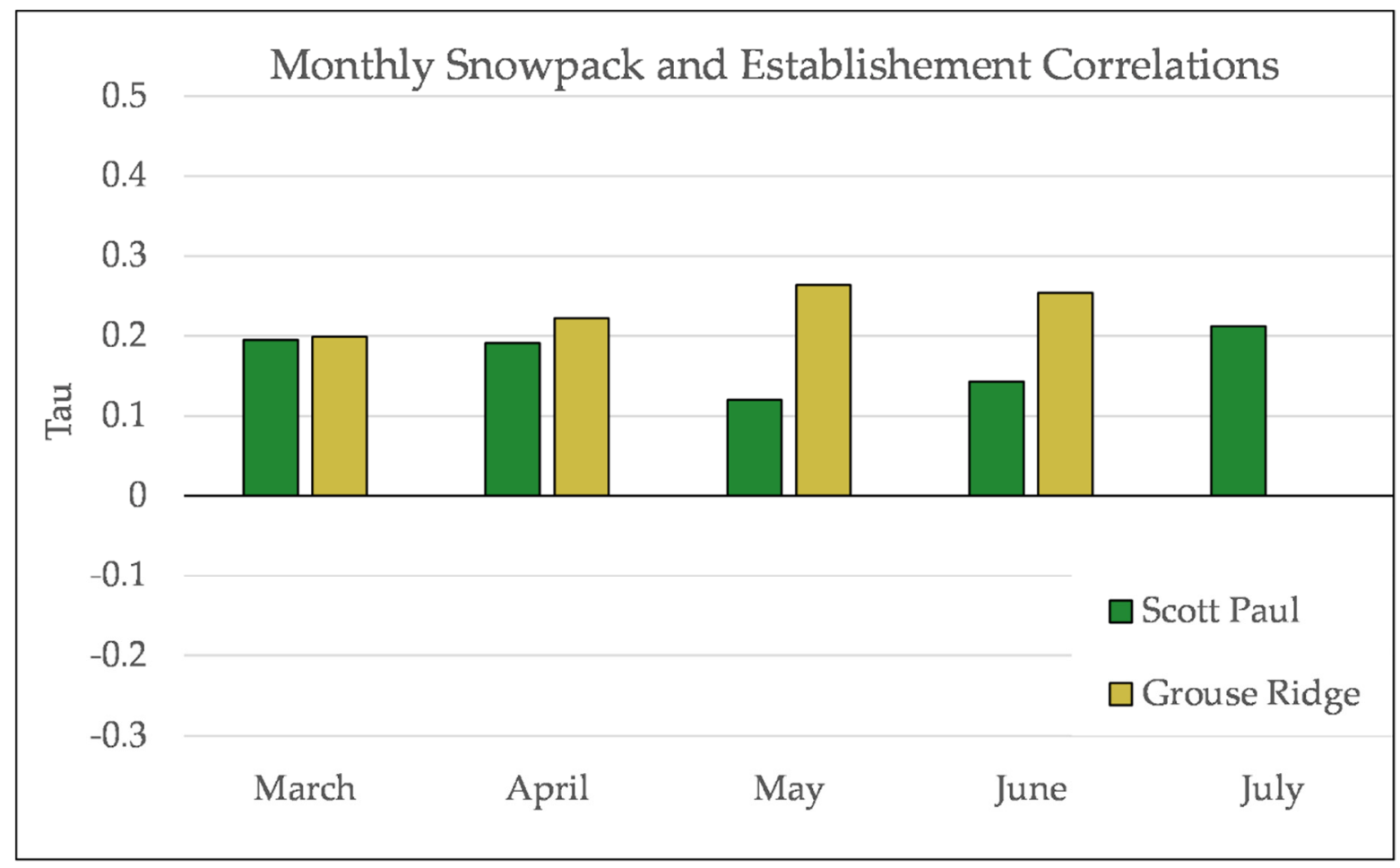

Figure 9. Partial Kendall's correlation controlled for temperature between snowfall and establishment at both sites. None of these correlations are significant. 


\subsection{Spatial Patterns}

While the temporal relationships between establishment and climate varied somewhat between sites, the spatial patterns were more consistent (Figure 10). We found that spatial relationships were significant at both the transect and study area scale of analysis.
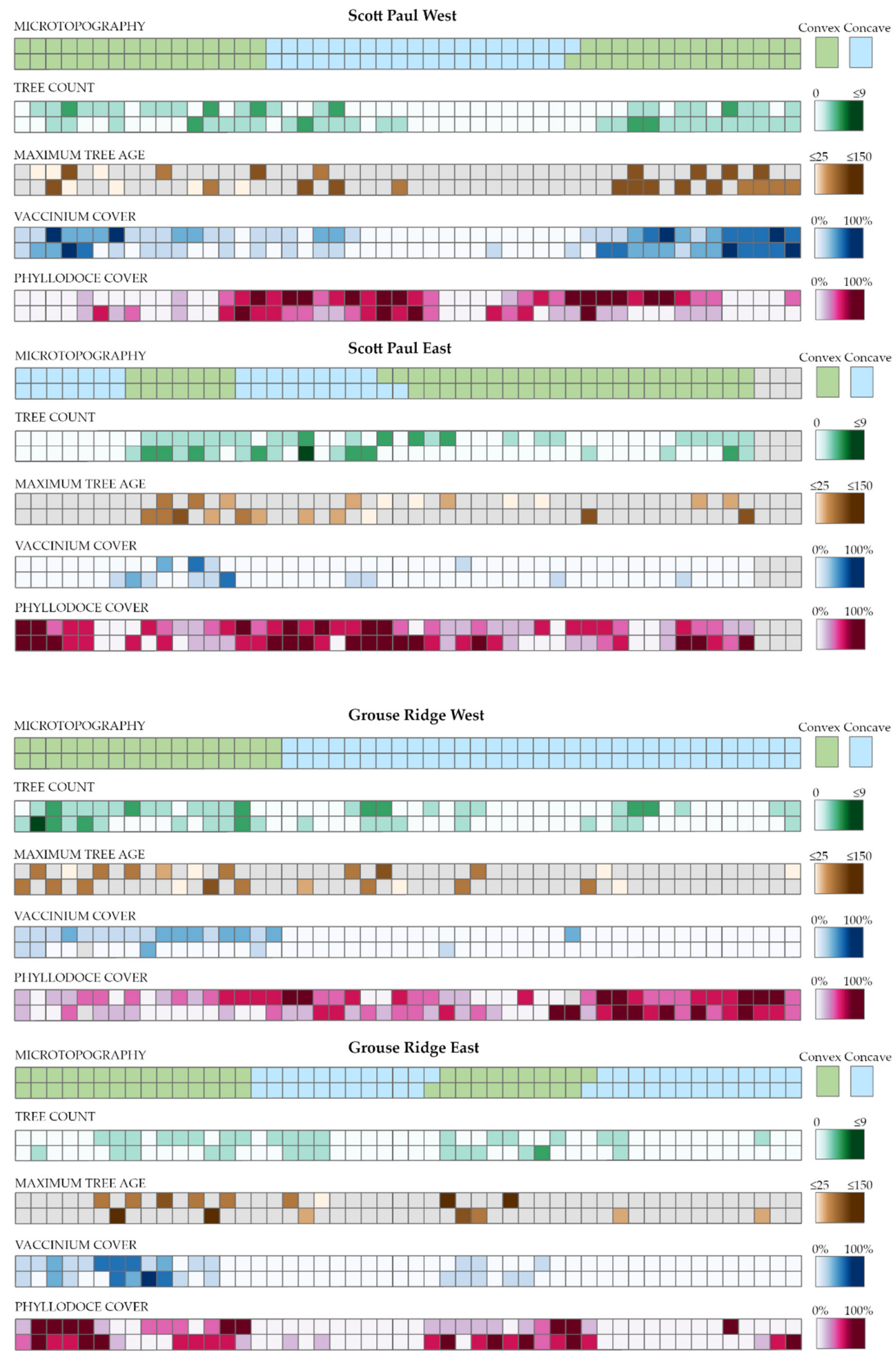

Figure 10. Spatial variables at each transect. Each grid cell corresponds to a square meter plot on a transect. Grid cells with no data for a particular variable are colored gray. Each transect begins at a seed source on the left side of the figure. 
The most consistent relationship was between density of established conifers and microtopography, with significantly denser establishment on convex plots compared to concave plots for all tree species present (Table 6). While the species have similar relationships with microtopography, there are differences when it comes to distance from seed source. There is no significant relationship between density of hemlock establishment and distance, but the density of silver fir decreases as distance from seed source increases (Table 7). We confirmed this result by running the same correlation using only convex plots. All transects started with convex plots, and we wanted to eliminate the possibility of a correlation with microtopography instead of distance. We confirmed our previous finding.

Table 6. The number of seedlings established in concave and convex plots.

\begin{tabular}{cccc}
\hline \multicolumn{2}{c}{ Microtopography-Wilcoxon Test } & & \\
\hline Concave N & Convex N & W & $p$-value \\
\hline 128 & 279 & 13,808 & $4.20 \times 10^{-8}$ \\
\hline
\end{tabular}

Table 7. Kendall's correlation between the density of trees established and distance from seed source for the whole study site.

\begin{tabular}{cccc}
\hline & \multicolumn{3}{c}{ Distance-Kendall's Correlation } \\
\hline \multirow{2}{*}{ All species } & $\mathrm{Z}$ & $\mathrm{Tau}$ & $p$-value \\
\cline { 2 - 4 } & -2.290 & -0.111 & 0.003 \\
\hline \multirow{2}{*}{ Mountain Hemlock } & $\mathrm{Z}$ & $\mathrm{Tau}$ & $p$-value \\
\cline { 2 - 4 } & 1.073 & -0.042 & 0.283 \\
\hline \multirow{2}{*}{ Silver Fir } & $\mathrm{Z}$ & Tau & $p$-value \\
\cline { 2 - 4 } & -6.203 & -0.252 & $5.545 \times 10^{-10}$ \\
\hline
\end{tabular}

There are also significant differences between the type of vegetation coverage and the density of establishment. While the combined percentage of heather and vaccinium does not significantly correlate with establishment density, when we separated the two cover types we found a significant but weak positive correlation with Vaccinium. This pattern was consistent between all transects (Table 8).

Table 8. Kendall's correlation between the density of establishment and different vegetation cover types for the whole study area.

\begin{tabular}{cccc}
\hline & \multicolumn{3}{c}{ Vegetation-Kendall's Correlation } \\
\hline \multirow{2}{*}{ Phyllodoce } & $\mathrm{Z}$ & Tau & $p$-value \\
\cline { 2 - 4 } & -0.880 & -0.003 & 0.379 \\
\hline \multirow{2}{*}{ Vaccinium } & $\mathrm{Z}$ & Tau & $p$-value \\
\cline { 2 - 4 } & 6.687 & 0.265 & $2.277 \times 10^{-11}$ \\
\hline
\end{tabular}

\subsection{Age Patterns}

The age range of seedlings sampled using whorl counts is from three to 43 years, while the age range of trees sampled using cross-sections was from 36 to 151 years. The median age of all samples combined is 47 years and the mean is 47.2 years. There are several interesting patterns to note as they relate to the age of the tree sampled. Spatially within the meadows there are no significant differences in how old the trees are in certain parts of the meadows compared to other parts of the meadow. There was no significant relationship between the age of trees in convex plots compared to concave plots (Figure 11) although the oldest trees were found only on convex surfaces, and convex surfaces had an 
older average tree age. There is a mix of patterns when looking at correlations between tree age and distance from seed source. Some transects show significant positive correlations, some show significant negative correlations, and some show no significant relationship at all (Figure 12).

\section{Influence of Microtopography on Tree Age}

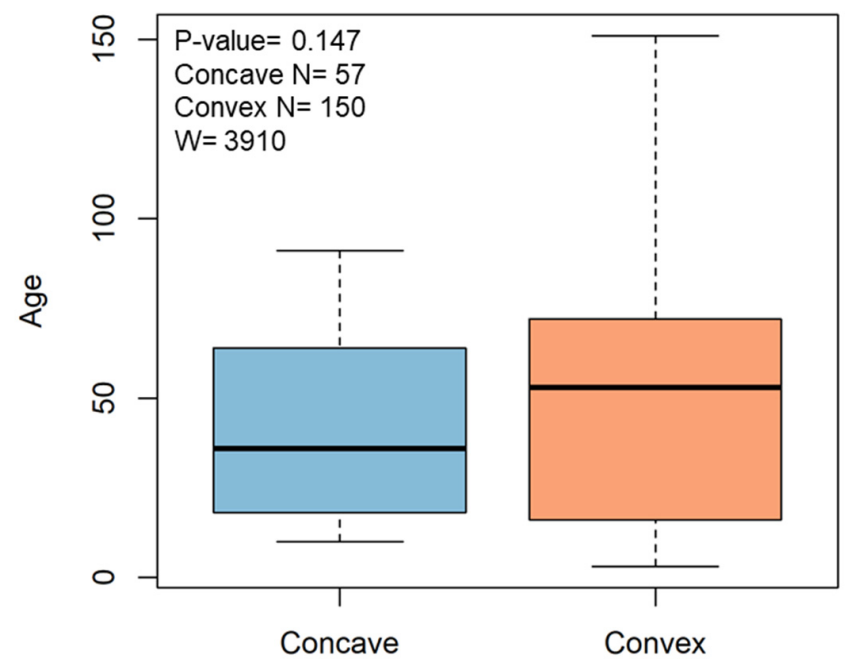

Topographic Position

Figure 11. The difference in the age of trees between concave and convex plots.

Influence of Seed Source Distance on Tree Age at SPW

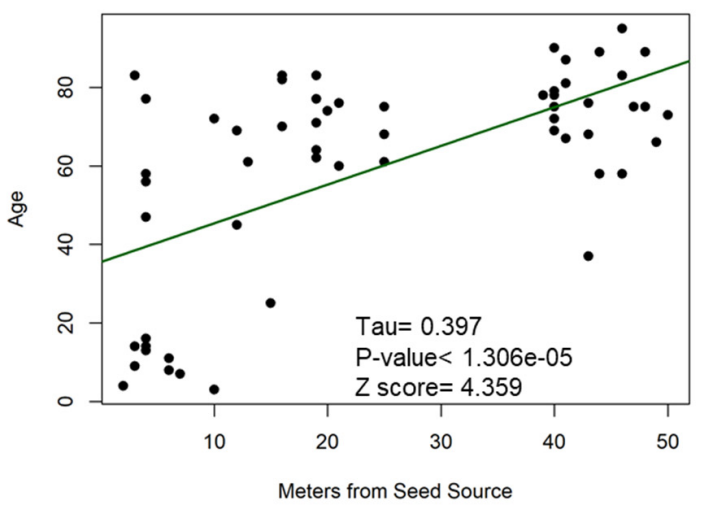

Influence of Seed Source Distance on Tree Age at GRW

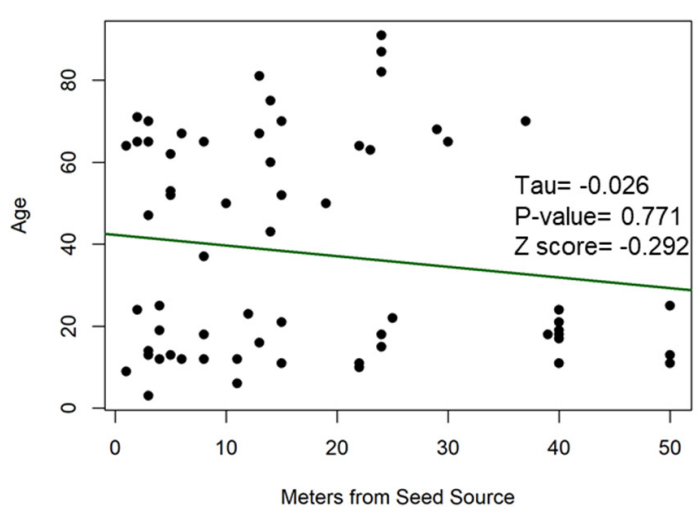

Influence of Seed Source Distance on Tree Age at SPE

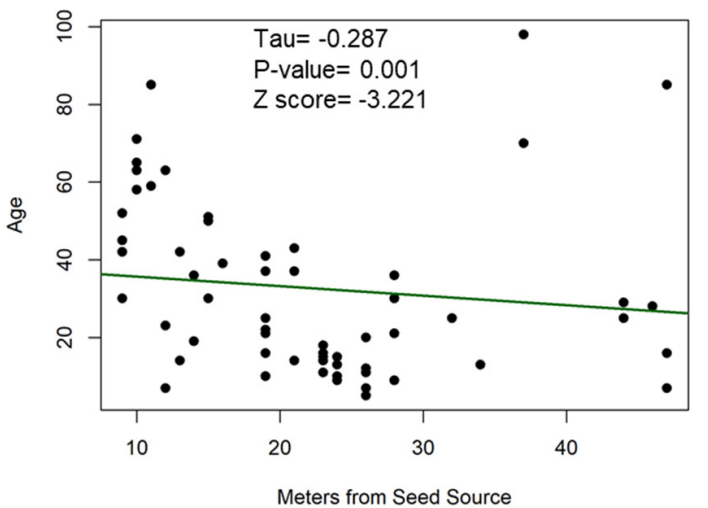

Influence of Seed Source Distance on Tree Age at GRE

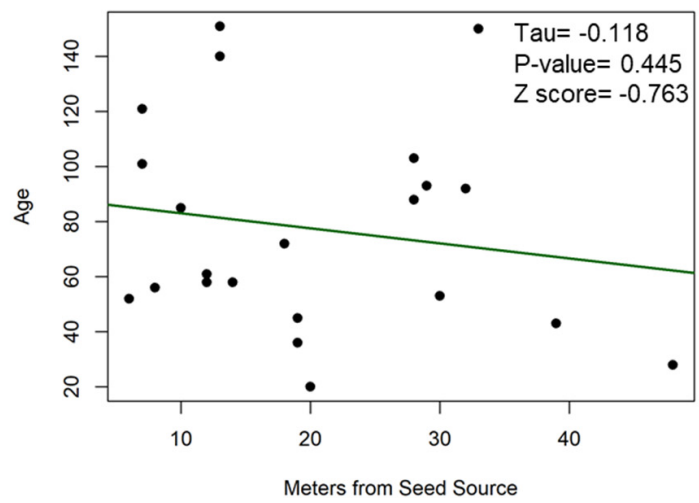

Figure 12. The relationship between tree age and distance from seed source at the individual transects. 
There are significant patterns in the relationship between tree measurements and the age of the tree. We chose to use a logarithmic transformation on the basal area and the height of the trees because after running the correlation without the log transformation there was a still a pattern in the residual plot (Figure A6). There are strong positive correlations between the age of trees and both their height and basal diameter (Figure 13) .
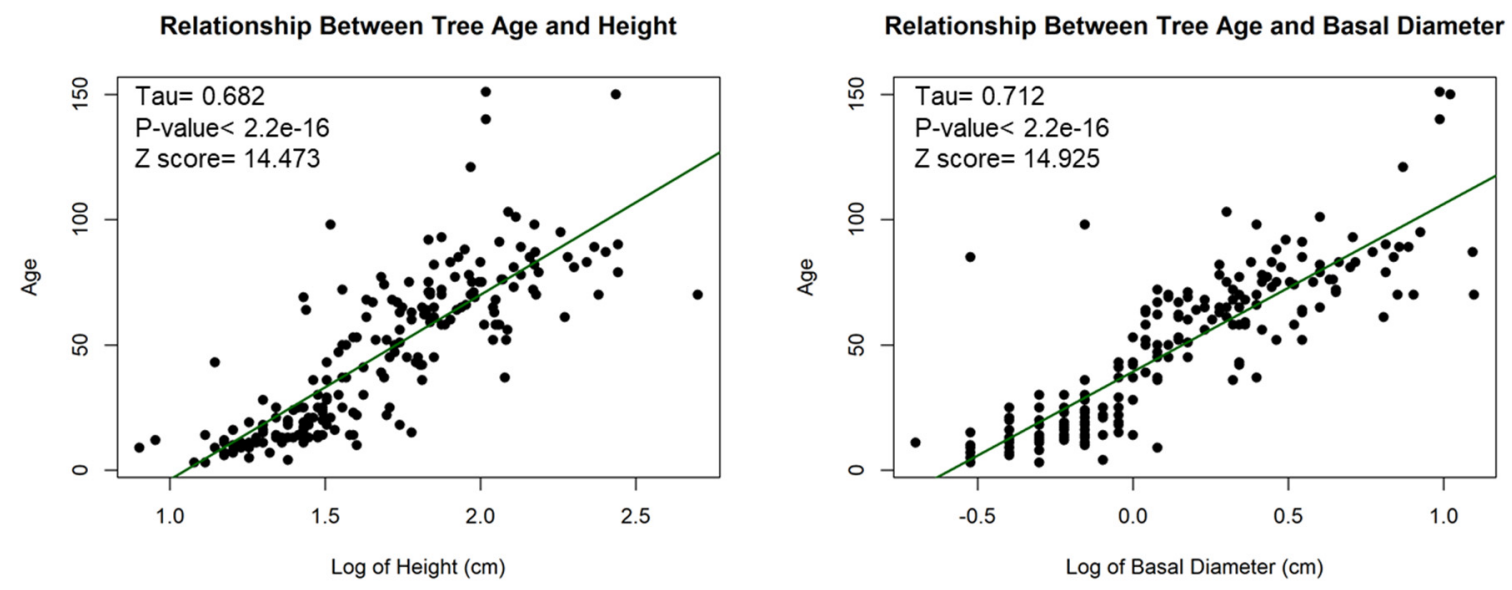

Figure 13. The relationship between log of basal diameter and tree age as well as log of height and tree age.

\section{Discussion}

\subsection{Establishment Pulses}

The overall trend is that there was little to no evidence of establishment in the late 1800s, followed by the onset of more consistent establishment in the early 1900s. More trees started establishing around Mt. Baker starting around 1926 and ending around 1960. There was then a lull for about 20 years, and then establishment began to increase again from 1981-2015. These pulses coincide with retreats of the Easton glacier, with the glacier response occurring almost a decade after the vegetation response [32]. However, the number and exact timing of establishment pulses varied among transects in response to local factors. For example, Scott Paul East only showed the most recent pulse, which we attribute to this meadow having experienced a relatively recent geomorphic disturbance. This is supported by the fact that a significant portion of the meadow vegetation was lupine, which we did not find at any of the other transects. Lupine is typically an early successional species, and its presence would make sense if this meadow were disturbed more recently than the other meadows [33]. The oldest trees at this site were all clustered on a topographically convex area that was not covered in lupine. Another possibility for the single pulse at Scott Paul East is katabatic winds off the Squak Glacier when it was closer during the early 1900s [32]. Scott Paul East is closer to a glacier than any other transect. Grouse Ridge East had low levels of establishment and no distinct pulses. It also has the oldest trees of any of the transects, which could indicate different growing conditions here despite its proximity to other sample sites. Other studies in the Washington Cascades have also shown that nearby study sites can have different establishment pulse histories $[10,12,15]$. The three different previously published studies on conifer establishment on Mt. Rainier each reported subtle differences in the timing of establishment pulses (Table 9) in spite of all using samples collected at relatively nearby sites on the south side of Mt. Rainier. While some of this has to do with the timing of the studies and the methods used, microclimates are also a factor in shifting when establishment pulses begin and end. At a coarse spatial scale establishment pulses are driven by climate, but at the local scale the influence of microclimate and disturbance history is strongly apparent. 
Table 9. Reported relationships between establishment and climatic and spatial variables in three previously published studies conducted at Paradise at Mt. Rainier.

\begin{tabular}{cccc}
\hline Results from Studies at Paradise & & & \\
\hline Establishment Pulses & Flower et al., 2017 & Rochefort and Peterson 1996 & Franklin et al., 1971 \\
\hline Microtopography & $1936-1970$ & $\begin{array}{c}\text { 1935-1950, 1955-1960, } \\
\text { 1980-1985 }\end{array}$ & 1928-1937 \\
\hline Distance to Seed Source & Convex (+) & Convex (+) & Convex (+) \\
\hline Vegetation & Not assessed & No significant correlation & No significant correlation \\
\hline Climate Variables & No significant correlation & $\begin{array}{c}\text { Greater in Heather } \\
\text { and Vaccinium }\end{array}$ & $\begin{array}{c}\text { Greater in Heather } \\
\text { and Vaccinium }\end{array}$ \\
\hline & $\begin{array}{c}\text { Mean annual and growing } \\
\text { season Temp (+), Mean } \\
\text { summer snowfall (-) }\end{array}$ & $\begin{array}{c}\text { May, June, July Temp (+) } \\
\text { PDSI, July Temp (+) }\end{array}$ \\
\hline
\end{tabular}

\subsection{Climate Patterns}

It is useful to analyze the climatic patterns at the Scott Paul and Grouse Ridge sites separately due to their different microclimates (Figures 2 and A7) and tree responses (Figures A8-A17 in Appendix A). Scott Paul is on a south-facing slope and has warmer temperatures than Grouse Ridge, but Scott Paul also gets more precipitation and much more snow. This leads to two different sets of limiting factors on establishment. At Scott Paul, the strongest limiting factor is snowpack in the growing season. Snow covers seedlings, decreasing light exposure and reducing temperatures during the growing season, both of which decrease rates of growth $[10,12,15]$. The biggest impacts on establishment happen in the months on either end of the growing season. In almost all months at Scott Paul, there is a weak positive correlation between temperature and establishment, which supports the conclusion that establishment is limited by temperature (Figure 6). The strongest correlation comes at the end of the growing season in September, when warmer temperatures can extend the growing season and change precipitation to rain instead of snow. Warmer growing season temperatures are also correlated with increased cone production in the following year for both mountain hemlock and subalpine fir [34]. Warmer growing seasons may therefore enable higher conifer establishment rates by influencing both seed production and seedling survival. However, it is important to remember that cone production in these species responds to a complex combination of multiple years of climate conditions, cone production in previous years, and other factors that influence carbohydrate storage [34].

There are few consistent patterns between establishment and precipitation at Scott Paul (Figure 6). The only consistent pattern is a strong positive correlation between establishment and precipitation in April, followed by a consistent negative correlation in May. This change in pattern demonstrates the importance of the timing of precipitation. Cloudy, cool conditions associated with higher May precipitation decrease the growth rate of trees and in turn shorten the growing season, while precipitation in April occurs before the growing season begins. April precipitation builds up the snowpack and recharges soil moisture, thus ameliorating drought stress over the growing season [35]. It is also possible that greater precipitation in April leads to a deeper snowpack, which protects seedlings from dramatic temperature swings and desiccation by wind [36,37], but the presence of the same pattern at Grouse Ridge, which is more moisture limited, indicates that it is more likely related to drought stress. Grouse Ridge has the opposite pattern of Scott Paul, with inconsistent relationships with temperature (Figure 6), and consistent positive correlations with precipitation, with the exception of May (Figure 7). Consistent precipitation and snowpack at Grouse Ridge reduces drought stress in the summer, but too much precipitation in May still reduces the length of the growing season. 
To summarize, the Scott Paul site is more temperature limited with the strongest positive correlation between establishment and temperature occurring at the end of the growing season in September, and Grouse Ridge is more precipitation limited with the strongest positive correlation between precipitation and establishment occurring in April, just before the start of the growing season.

Scott Paul, which is more snow limited, sees a decrease in correlation strength between establishment and snowpack between April and May (Figure 8). This supports the conclusion that snow is limiting establishment at this site. The slight increase in correlation strength from May through July reflects the importance of snowpack to soil moisture. Snowpack will decrease throughout the growing season regardless, and there is a point at the beginning of the growing season where reducing it allows temperatures and exposure to sunlight to increase, but complete snowmelt contributes to drought stress. This is also supported by the decrease in correlation strength for snowfall (Figure 9) from April to May. We did not extend our correlations beyond May, due the extremely limited number of years in which there was snowfall in growing season months beyond May. At Grouse Ridge, the correlations are less consistent. However, it is still possible to see a decrease in correlation strength between April and May for both snowpack (Figure 8) and snowfall (Figure 9).

\subsection{Spatial Patterns}

The best scale of analysis for spatial patterns is the transect scale. However, spatial patterns were quite consistent between transects, and the results found at the transect level were also true for the whole study area. There was more establishment on convex plots than concave plots. This is likely due to earlier snowmelt creating a longer growing season on convex surfaces, which leads to increase chances of survival [12,15]. This relationship is well established in the literature but has yet to be thoroughly tested at these sites. Future research would benefit from analyzing actual differences in snowmelt timing within individual meadows.

We attempted to see if there was a difference between Phyllodoce and Vaccinium with regards to establishment, and ended up with mixed results. We found that there was a consistent, weak, positive correlation between Vaccinium and conifer establishment, but no relationship with Phyllodoce. This differs from the findings of Flower et. al, 2017, the only other study to try and make the distinction, which found no relationship between either. Although Vaccinium is more common on convex surfaces, when controlling for topographic position we found that a weak positive association with conifer density still remained. Some research suggests there may be mycorrhizal associations between Vaccinium species and conifers that could facilitate conifer establishment [12,38]. Meadow soils around Mt. Baker have a very thin organic layer, and it is possible that the loss of leaves from Vaccinium species could increase the amount of organic matter in the soil compared to the evergreen Phyllodoce species which would not do so as quickly [39]. Increased soil carbon would create slightly more favorable establishment conditions in areas with a greater density of Vaccinium [39]. Further study is necessary to determine exactly what differences there may be between Phyllodoce and Vaccinium cover.

There were also species-level differences with the correlation between establishment density and distance from seed source. Mountain hemlocks with their light seeds had no relationship to seed source distance, while silver fir density was negatively correlated with distance from seed source due to its heavier seeds. This is similar to what was found on Mt. Rainier for mountain hemlock. Silver fir was not a large component of any study on Mt. Rainier, but it has been noted in other studies that Pacific silver fir's seeds do not disperse as far [40]. The strong similarities in spatial patterns at all our transects, as well as in previous studies, further supports the conclusion that the fine scale controls on establishment patterns within a single meadow are consistent between meadows, even if the larger scale average climate conditions at those meadows are different. Trees are most likely to establish on convex surfaces, usually in patches of Phyllodoce and Vaccinium which can facilitate growth, and silver fir is particularly limited in the distance that it can disperse. 


\subsection{Age Patterns}

We found no significant spatial relationships for the ages of trees. We analyzed both the difference in ages of trees on convex and concave plots (Figure 11), as well as how age correlated to distance from seed source (Figure 12). This indicates that when trees establish in pulses, they are gradually filling in all suitable areas over time, such as convex areas with Vaccinium coverage, rather than first filling in the most suitable areas for establishment prior to establishing in slightly less suitable microsites. This is slightly different from the findings of Flower et al., 2017, which is the only other study in the region to have analyzed spatial age patterns of subalpine conifer encroachment. They found that trees in convex plots were significantly older than trees in concave plots. At Mt. Baker, we found trees were consistently older on convex plots, but the relationship was not statistically significant. The difference in the findings between the two studies indicates that there are slight differences in spatiotemporal availability of habitat for establishment between Mt. Baker and Mt. Rainier. At both Mt. Rainier and Mt. Baker, convex surfaces became suitable for the onset of establishment earlier in the 20th century than concave surfaces, but the relationship is stronger at Mt. Rainier.

We also found significant positive correlations between basal diameter and age, as well as height and age. Flower et al., (2017) found only a significant positive relationship between height and age. At Mt. Rainier it was more beneficial for seedlings to put more of their resources into growing vertically, most likely to have more of their needles exposed to warmth and sunlight above the snowpack in the early growing season. At Mt. Baker the seedlings put as many resources into growing vertically as they did into increasing in width, with similar correlations between height and age, and basal diameter and age (Figure 14). Most trees were growing vertically with one single stem, except for yellow cedar which occasionally grew vertically with multiple stems. None of the samples came from Krumholtz trees, as there were none in our transects. According to data from a SNOTEL site reported by the Natural Resource Conservation Service, early season snowpack at Paradise is consistently deeper than it is at Mt. Baker, which could account for the differences in growth patterns if they reflect stronger limitation by deep snowpack at Mt. Rainier (Figure A7).

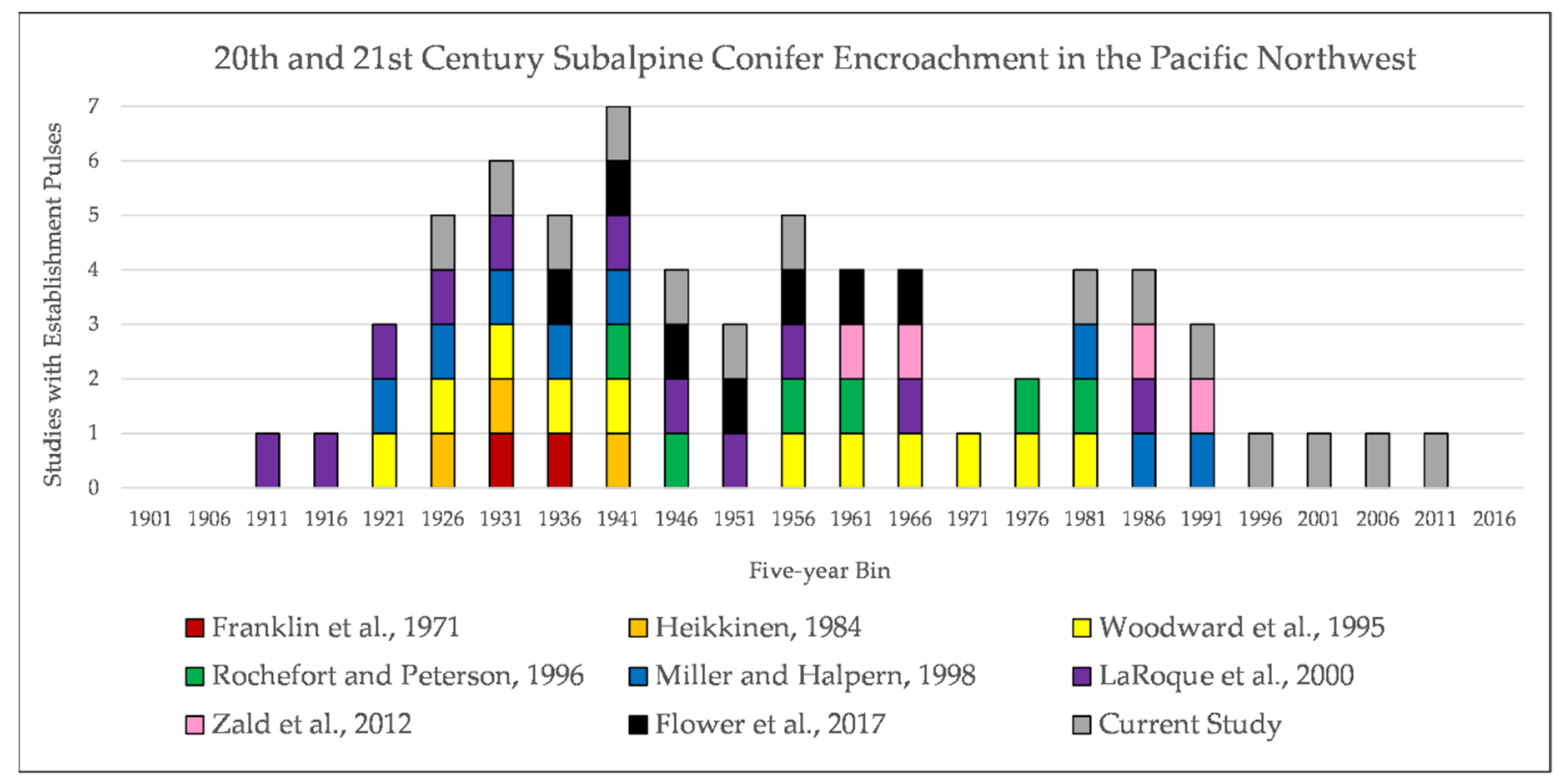

Figure 14. Pulses of conifer establishment using nine different studies in the Pacific Northwest. 


\subsection{Regional Patterns}

There are generally consistent patterns in the timing of conifer encroachment throughout the Pacific Northwest. These patterns are driven by regional climatic changes, as well as differences in aspect, microclimate, and tree species present between sites. The general trend for the region is a nearly continuous period of establishment from early 1920s through the 1960s, with pulses in the early 1930s and early 1940s (Figure 9). This period of establishment is followed by another pulse, starting in the 1980s and ending in the early 1990s. A pulse, sometimes also referred to as a peak, has neither a precise nor consistent definition, but is generally used to refer to a period of time when there is greater than normal levels of seedling establishment.

Our research at Mt. Baker fits well within the regional patterns of conifer encroachment, while also showing some key location-specific differences. The only previous study on forest expansion in the subalpine zone at Mt. Baker showed that there was a correlation between periods of establishment and periods of higher temperatures and lower precipitation [41]. The author also noted that there was a correlation between aspect and establishment, with aspects that receive more solar radiation having higher rates of establishment. In the Pacific Northwest, conifer encroachment has been most frequently studied around Mt. Rainer. Mt. Rainier has a variety of microclimates in the subalpine zone due to changes in precipitation around the mountain [12]. With wind direction and orographic uplift, the west side of the mountain has greater precipitation and deeper snowpack than the east side. This difference in climate creates conditions favorable to different tree species at various times, resulting in different temporal patterns of establishment. On the south and west sides of Mt. Rainier, establishment increased when summer temperatures were warmer, when summer snowfall was lower, and when PDSI was higher [10,12,15]. While on the northeast side, encroachment increased during periods of lower summer temperatures, increased summer precipitation, and increased PDSI [12]. Similarly, at our sites on Mt Baker, establishment at our drier site was more strongly correlated with moisture availability, and establishment at our site with heavier snowpack is more strongly correlated with temperature. Unexpectedly, our dry site is on a north facing slope. There are likely local topographic affects that causes a difference in precipitation between Scott Paul and Grouse Ridge.

Our individual transects at Mt. Baker showed varying timing of establishment pulses, even at nearby transects, but consistent relationships between establishment density and spatial variables. This pattern has also been observed at Mt. Rainier. Paradise, a popular tourist destination on the south side of Mt. Rainier, has been studied more frequently than other locations around the mountain. Even though all sites at Paradise experience similar climates and have similar assemblages of tree species, and encroachment at these sites has a fairly similar relationship to changes in climate, each study found different periods of time with pulses of establishment $[10,12,15]$. This is likely due to microclimatic differences between sites caused by local variability in factors such as slope aspect [15]. While the temporal patterns on different sides of a mountain and even at similar sites might be variable, the spatial patterns of where trees are establishing in the meadows is consistent across all locations (Table 9). Trees tend to establish more densely on microtopographic convexities as well as within the areas covered with Phyllodoce/Vaccinium community, and with no significant relationship to the distance from a seed source $[10,12,15]$. These are generally the same relationships we observed at Mt. Baker. While there may be regional and landscape scale differences in climate, microclimates within meadows tend to create areas that are more favorable for establishment, and the characteristics of favorable microclimates in meadows are consistent throughout the region.

Similar temporal and spatial patterns are also found outside the Washington Cascades in similar climatic regions. In the Olympic Mountains, mountain hemlock established more frequently on the wetter end of a precipitation gradient during drier periods in the 20th century, while on the drier end of the gradient subalpine fir established more frequently during wetter portions of the 20th century [11]. There is also denser establishment in 
Phyllodoce/Vaccinium cover than in other types of vegetation cover. On southern Vancouver Island, mountain hemlock establishment was greatest during periods with low snowpack and normal summer temperatures, or warmer than normal summers with moderately deep snowpack [14]. This fits with the pattern on the west side of Mt. Rainier, the Olympics, and at Scott Paul where conifer establishment is more successful when snow melts fast enough to increase the growing season, but not so much that it creates drought conditions. Silver fir and subalpine fir on Vancouver Island established more during cool growing seasons with moderately deep snowpack, but likely for different reasons, as subalpine fir tends to grow in more drought prone microsites and silver fir grows in mesic sites but is extremely drought intolerant [14].

There are similar divides in temporal patterns of establishment in Oregon, but instead of a west to east precipitation gradient they found a difference between north and south facing slopes due to changes in radiation [13]. South-facing slopes showed similar patterns of establishment to sites on the east side of Mt. Rainier with establishment occurring during wetter periods, while north facing slopes were more like the west side. Spatially, in Oregon they found that within meadows the type of landform on which establishment is occurring influences how densely trees established. The landform modifies the depth of the snowpack, which in turn changes the length of the growing season, which is consistent with the regional pattern [16]. At Mt. Baker, the south-facing slopes were more like the west side of Mt. Rainier, and the north-facing slope more like the east side of Mt. Rainier. This is the exact opposite of the pattern found in Oregon and is so far unique to Mt. Baker. However, both Oregon and Mt. Baker showed similar spatial patterns of establishment, with landforms in meadows providing more or less suitable habitat depending on microclimatic conditions.

\section{Conclusions}

We investigated conifer encroachment into subalpine meadows on Mt. Baker using dendrochronological methods. We set out to reconstruct the local history of conifer seedling establishment and quantify the spatiotemporal relationships between establishment and a suite of climatic, ecological, and topographic variables. The timing of establishment pulses, during which many conifer seedlings successfully established over a short time period, were broadly similar to the dates reported for other mountains in the region. We found the onset of consistent establishment began in early 1900s, and that there were two major pulses of establishment: 1926-1930 through 1956-1960 and 1981-1985 through 2011-2015. We found that across our study area, establishment was correlated with warmer temperatures and a longer growing season. At the site level, establishment at our wetter, snowier site was primarily limited by growing season length and was therefore positively correlated with temperature, particularly at the end of the growing season. Establishment at our more moisture limited site was positively correlated with precipitation.

Seedlings established in favorable spots within each meadow, which lead to patchy patterns of encroachment. Establishment density was higher and trees were older in areas with convex microtopography, where snow melts earlier in the year. and lower in areas with concave microtopography. Establishment density was also higher in areas with denser Vaccinium coverage but showed no relationship with Phyllodoce coverage.

The subalpine ecotone, like many ecosystems, is already changing in response to climate change [42,43]. Conifer encroachment is reducing critical meadow habitat, making it more challenging for species that either live solely in that habitat or depend on it for food or shelter. In areas that are more limited by snow, conifers will encroach into previously treeless areas during periods of time that are warmer and drier, particularly in the growing season. Growing seasons are predicted to become longer, warmer, and drier as climate change continues over the 21st century [44] which will likely lead to increased rates of conifer encroachment into many subalpine meadows. Other areas are more moisture limited and may see decreased establishment during those periods due to drought stress. This results in spatial variability in habitat loss, leaving species in some 
areas with less habitat and generally reducing habitat connectivity. Some meadows are also more suitable for establishment than others due to the presence of convex surfaces and increased vaccinium cover, which will increase the spatial variability of habitat loss. The forest that takes the place of the meadows likely will look different than the forest that exists currently, with different species responding individualistically depending on their climatic tolerances and seed dispersal abilities. While we did identify similarities in the timing of conifer establishment pulses between our studies and previously published records for other mountains in the region, there are enough differences between mountains, and even between multiple sites on Mount Baker itself, that it is clear that research must be conducted more widely to fully illuminate the spatial and temporal patterns of changes occurring in subalpine meadows.

Author Contributions: Conceptualization, B.H. and A.F.; Methodology, B.H. and A.F.; Validation, B.H. and A.F.; Formal analysis, B.H.; Resources, A.F.; Data curation, B.H.; Writing-original draft preparation, B.H.; Writing-review and editing, B.H. and A.F.; Supervision, A.F.; Project administration, B.H. and A.F.; Funding acquisition, B.H and A.F. Both authors have read and agreed to the published version of the manuscript.

Funding: This research was funded by Western Washington University and Huxley College of the Environment through the Huxley Small Grant.

Institutional Review Board Statement: Not Applicable.

Informed Consent Statement: Not Applicable.

Data Availability Statement: Climate data used in our research can be found in these locations: https: / / sites.ualberta.ca/ ahamann/data/climatewna.html (accessed on 14 September 2021) and https: / / www.sciencebase.gov/catalog/item/594c2e2fe4b062508e385612 (accessed on 14 September 2021).

Acknowledgments: Thank you to Hannah LaGassey, Lin Hagedorn, Tom Hagedorn, Elliot Winter, Jameson Goff, Shea Simpson, Mia Henderson, Michael Schroeder, Sean Fitzpatrick, Bill LaGassey, Rai Dachenhausen, and Colter Lemons for help collecting and processing the many samples used in this study. We are indebted to Andy Bach, Michael Medler, Eric DeChaine, and Andy Bunn for their advice and comments.

Conflicts of Interest: The authors declare no conflict of interest.

\section{Appendix A}

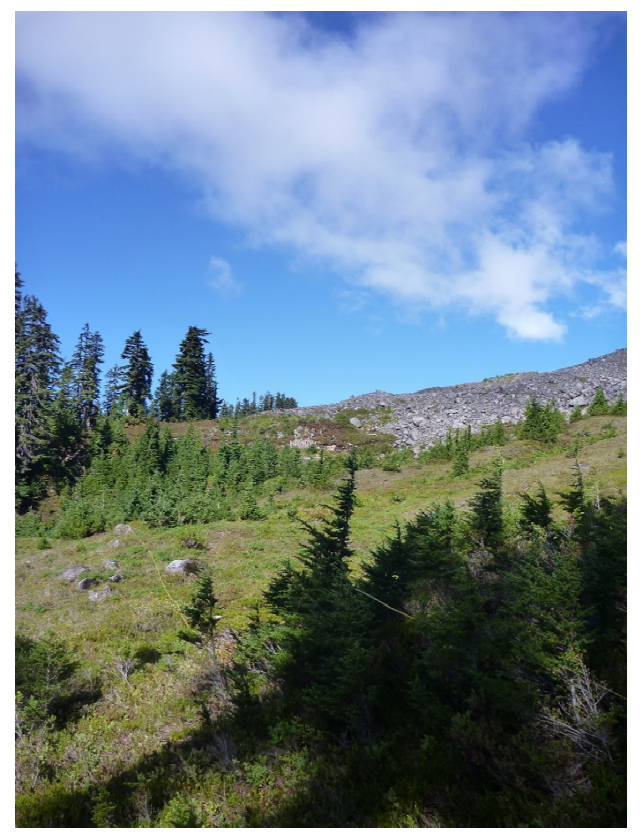

Figure A1. Scott Paul East transect crosses a meadow directly below end moraines Squak glacier. 


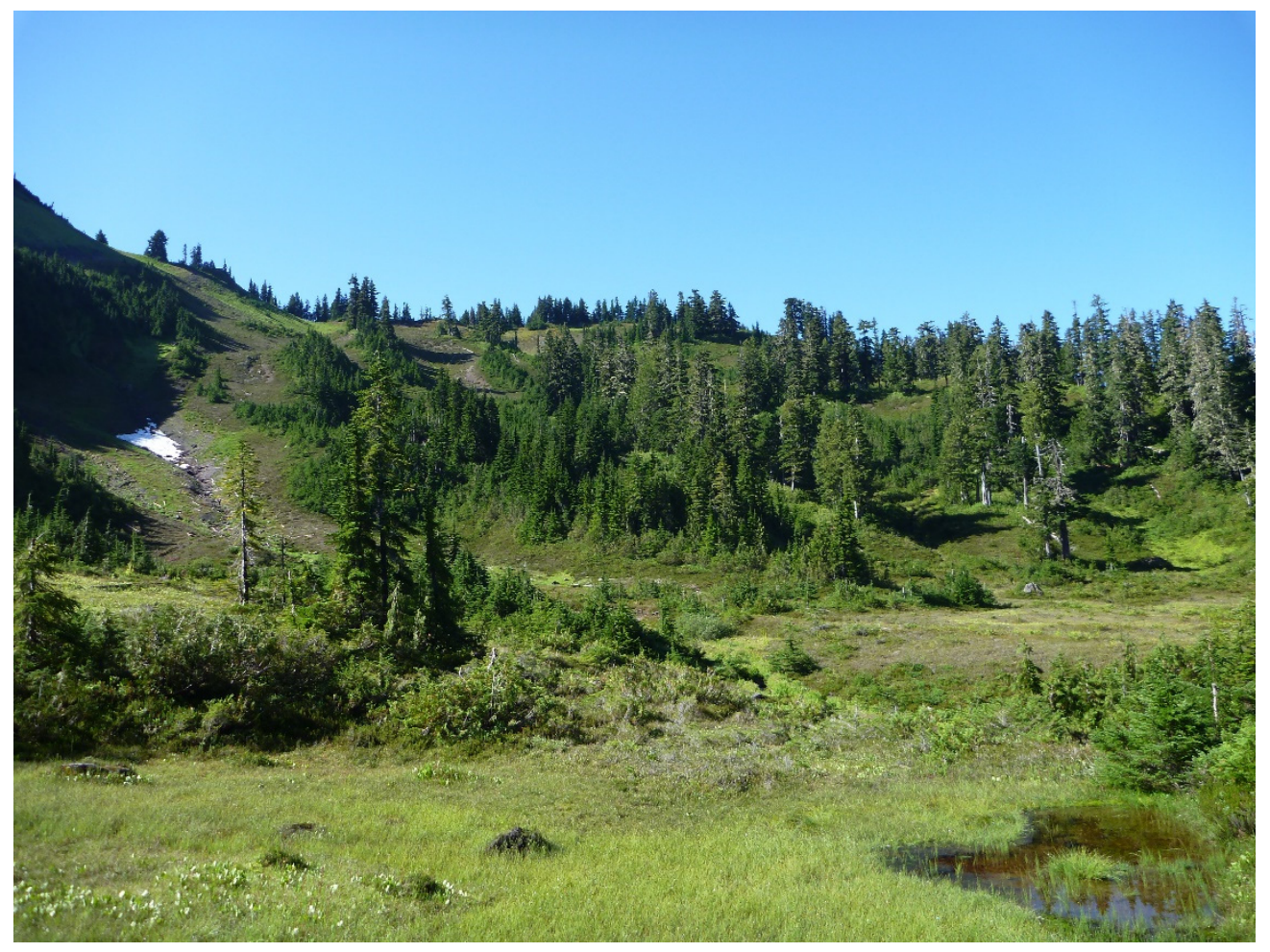

Figure A2. The Grouse Ridge site sits at the head of a glacially carved valley.

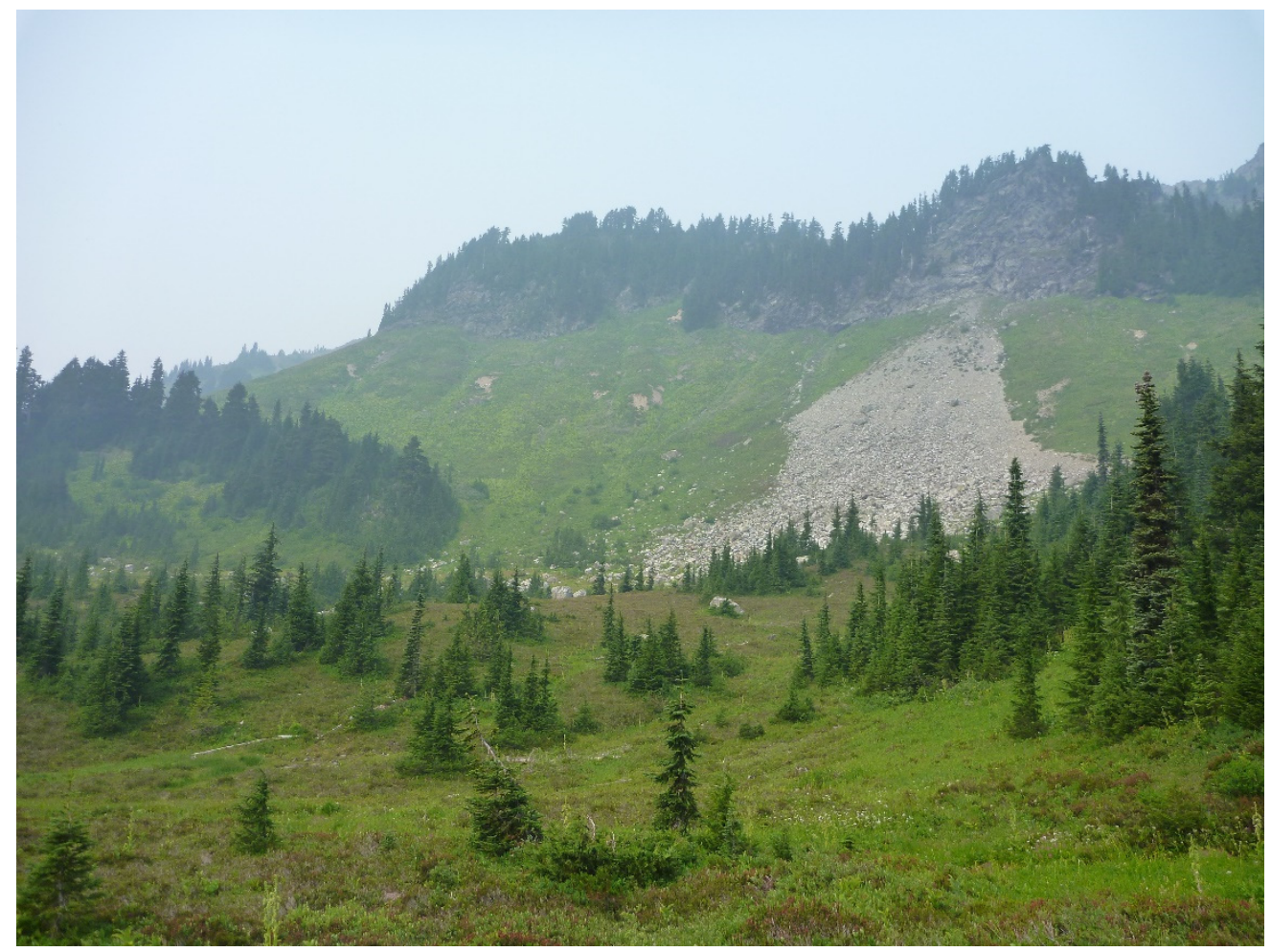

Figure A3. A recent mass wasting event just above a meadow near our study sites. 


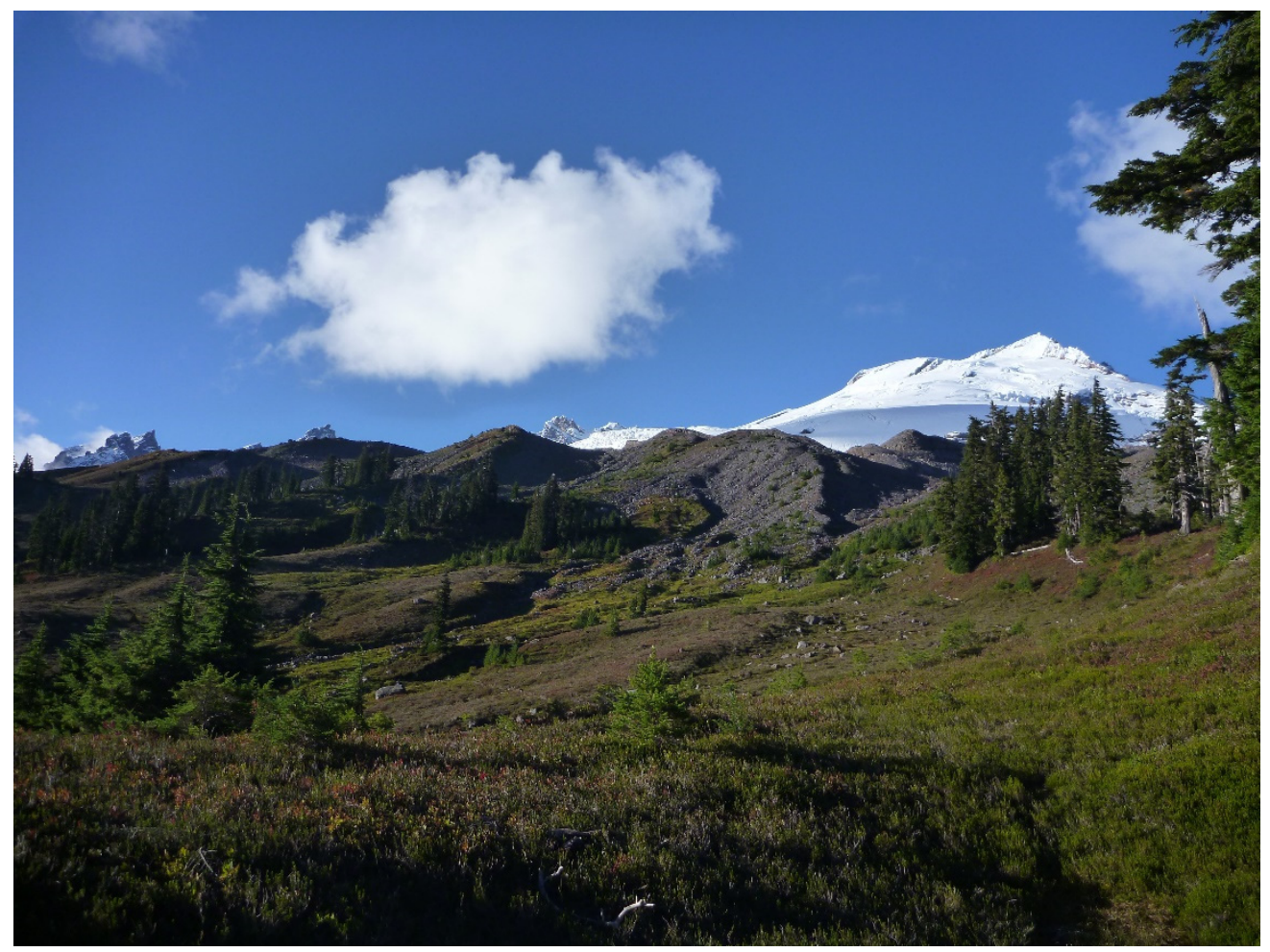

Figure A4. End moraines above the Scott Paul site and the uneven terrain below them left by previous mass wasting events.

Relationship Between Annual Temperature and Annual Precipitation

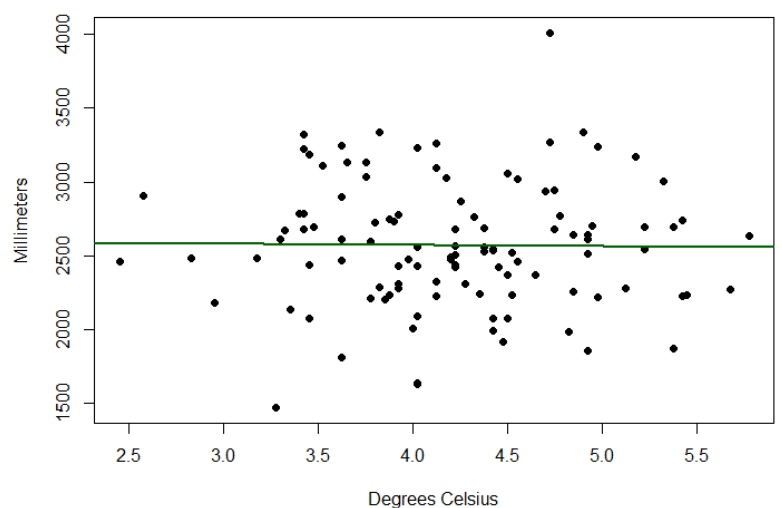

Relationship Between May Temperature and Precipitation

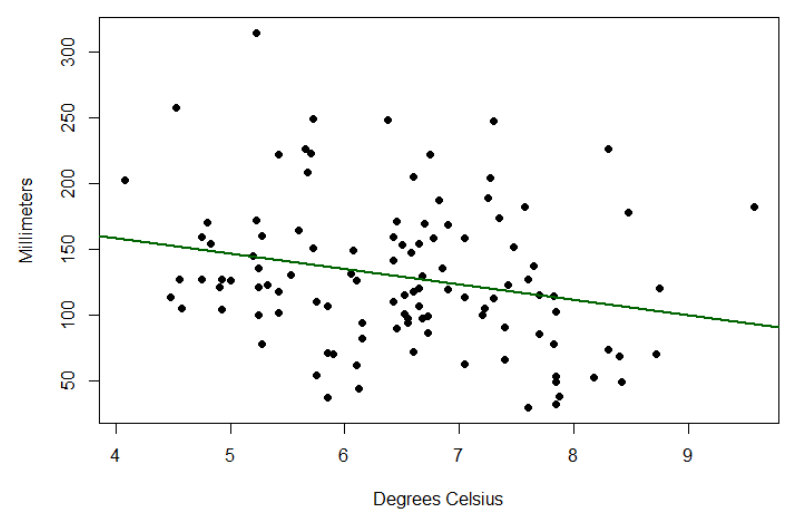

Relationship Between May Precipitation and Snowpack

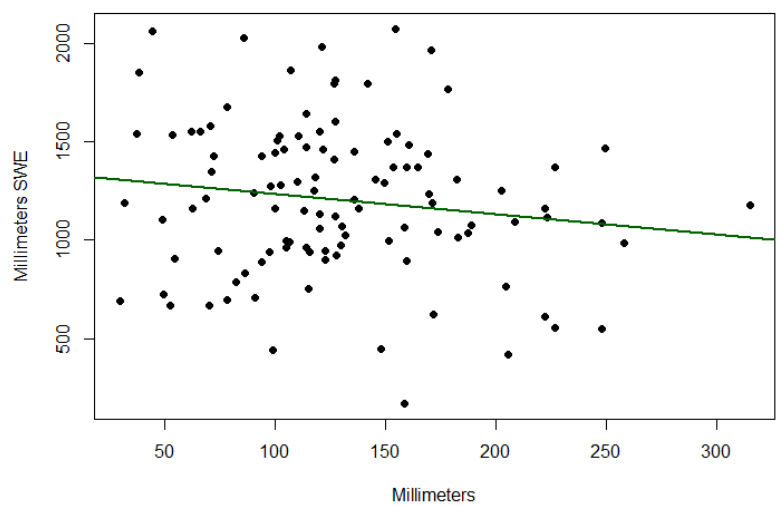

Relationship Between May Temperature and Snowpack

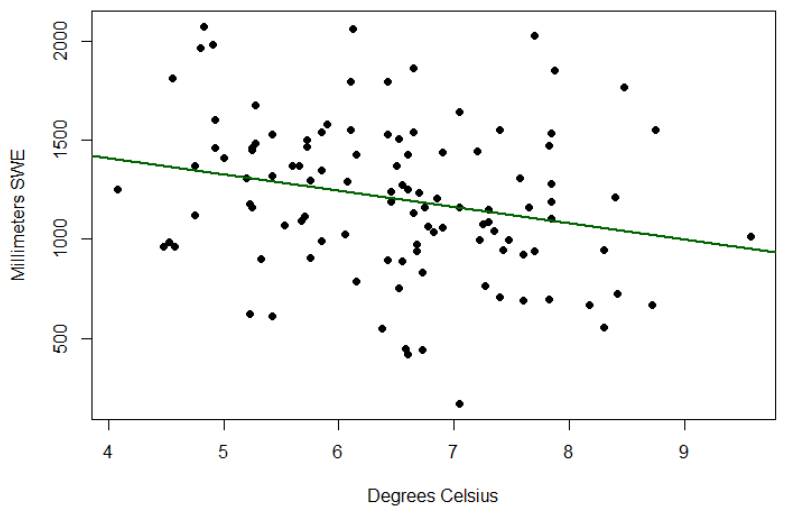

Figure A5. Cont. 


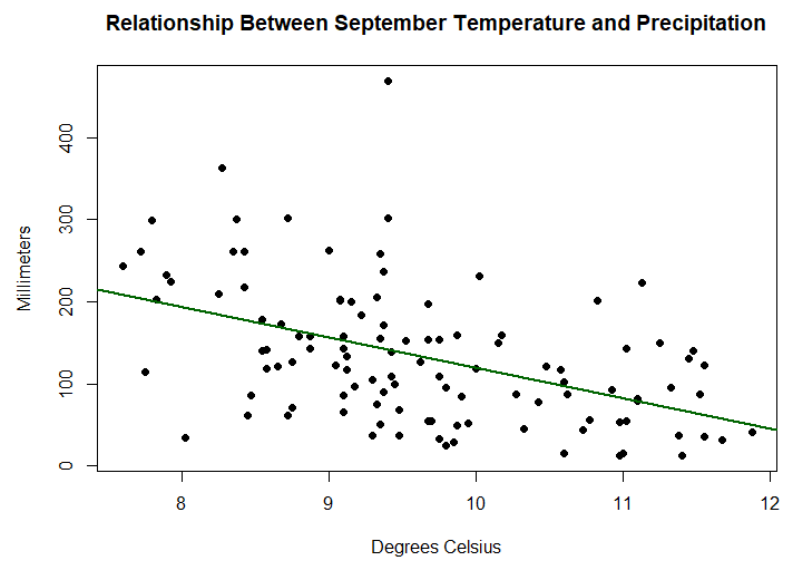

Figure A5. Shows the correlations between different climate variables.

Table A1. Shows the values for the correlations shown in Figure A5.

\begin{tabular}{ccccr}
\hline Climate Variable Correlations & T-Score & $\begin{array}{c}\text { Degrees of } \\
\text { Freedom }\end{array}$ & $p$-Value & R \\
\hline MAT and MAP & -0.165 & 108 & 0.869 & -0.016 \\
\hline May Temp and Precip & -2.556 & 108 & 0.012 & -2.388 \\
\hline September Temp and Precip & -5.537 & 108 & $2.182 \times 10^{-7}$ & -0.470 \\
\hline May Precip and Snowpack & -1.543 & 108 & 0.1257 & -0.147 \\
\hline May Temp and Snowpack & -2.58 & 108 & 0.011 & -0.241 \\
\hline
\end{tabular}

Table A2. Shows consistently significant $p$-values for the Shapiro-Wilkes test, which indicates that data is not normally distributed.

\begin{tabular}{cccccccc}
\hline $\begin{array}{c}\text { Shapiro Test } \\
p \text {-Values }\end{array}$ & \multicolumn{1}{c}{ The } & & & & \\
\hline & Phylo. & Vacc. & Lupinus & TSME & ABAM & CANO & All Trees \\
\hline GRW18 & 0.001 & $5.73 \times 10^{-10}$ & NA & $<2.2 \times 10^{-16}$ & $1.52 \times 10^{-15}$ & $<2.2 \times 10^{-16}$ & $1.72 \times 10^{-12}$ \\
\hline GRE18 & $3.87 \times 10^{-8}$ & $6.61 \times 10^{-10}$ & NA & $<2.2 \times 10^{-16}$ & $<2.2 \times 10^{-16}$ & $<2.2 \times 10^{-16}$ & $2.80 \times 10^{-15}$ \\
\hline SPW18 & $3.68 \times 10^{-6}$ & $2.88 \times 10^{-5}$ & NA & $1.35 \times 10^{-12}$ & $<2.2 \times 10^{-16}$ & NA & $9.64 \times 10^{-11}$ \\
\hline SPE18 & $3.98 \times 10^{-5}$ & $6.00 \times 10^{-10}$ & $4.99 \times 10^{-11}$ & $1.45 \times 10^{-12}$ & $<2.2 \times 10^{-16}$ & NA & $4.27 \times 10^{-12}$ \\
\hline
\end{tabular}

Table A3. Shows consistently significant $p$-values for the Fligner-Killeen test, which indicates that data is not homoscedastic.

\begin{tabular}{lccccccc}
\hline $\begin{array}{c}\text { Fligner Test } \\
p \text {-Values }\end{array}$ & \multicolumn{10}{c}{} & & & & \\
\hline & Phylo. & Vacc. & Lupinus & TSME & ABAM & CANO & All Trees \\
\hline & 0.007 & $1.02 \times 10^{-10}$ & $<2.2 \times 10^{-16}$ & $7.01 \times 10^{-7}$ & $1.25 \times 10^{-8}$ & $3.98 \times 10^{-10}$ & 0.0001 \\
\hline
\end{tabular}



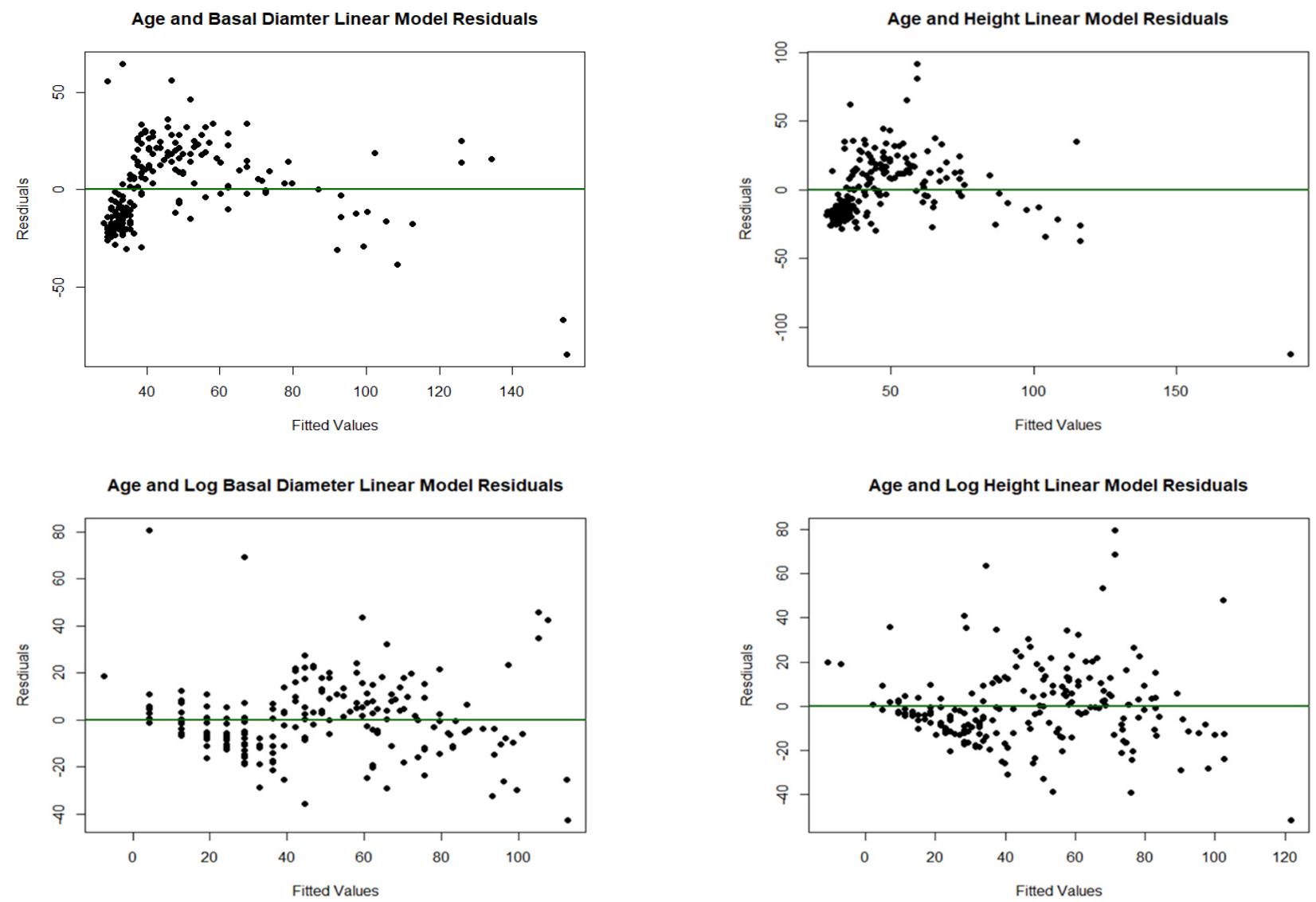

Figure A6. Shows the difference between the transformed and untransformed residuals for linear models built to show the relationships between age and growth of trees.

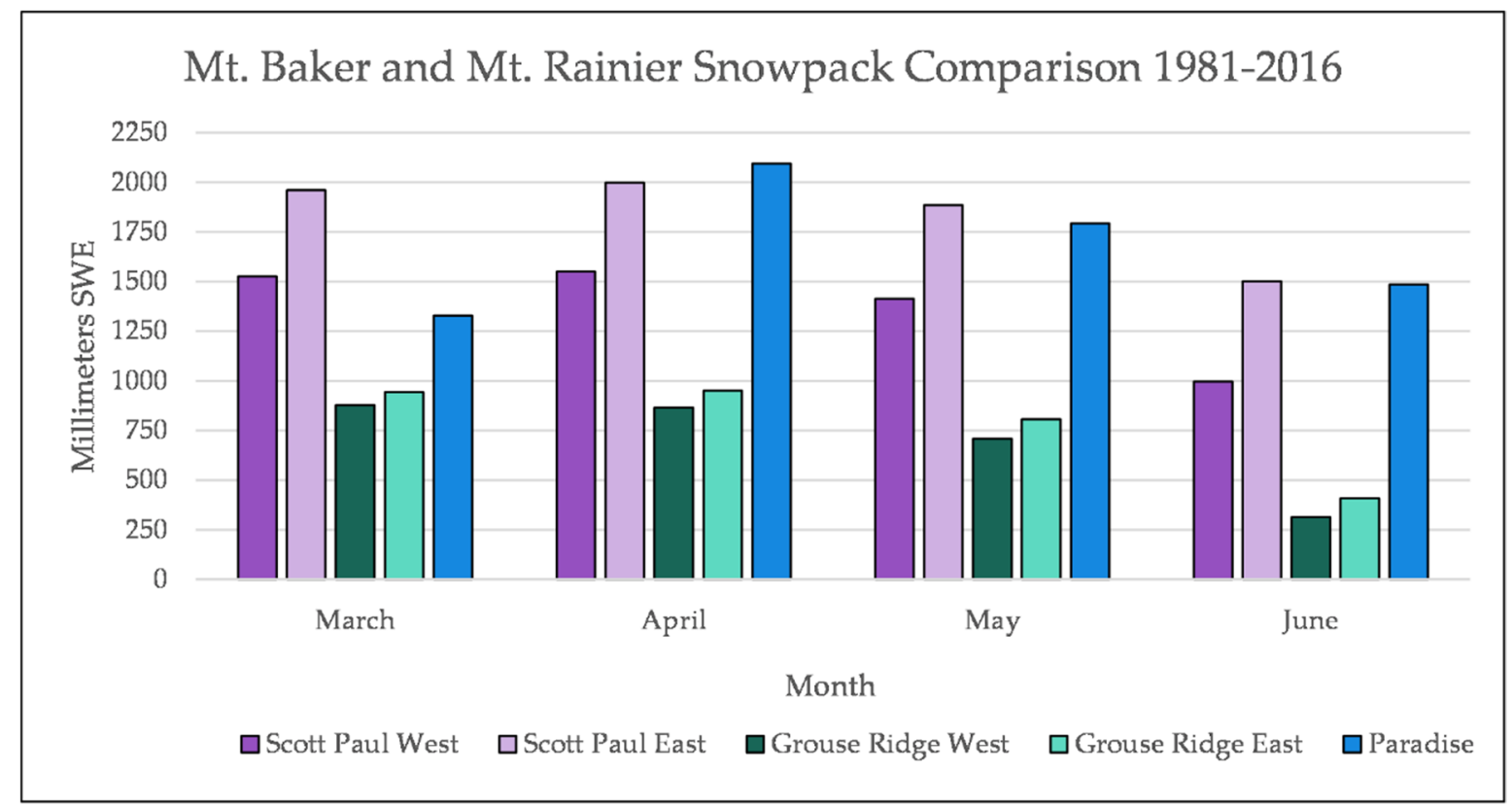

Figure A7. A comparison of early growing season snowpack at Mt. Baker Transects and at Paradise on the south side of Mt. Rainier. 


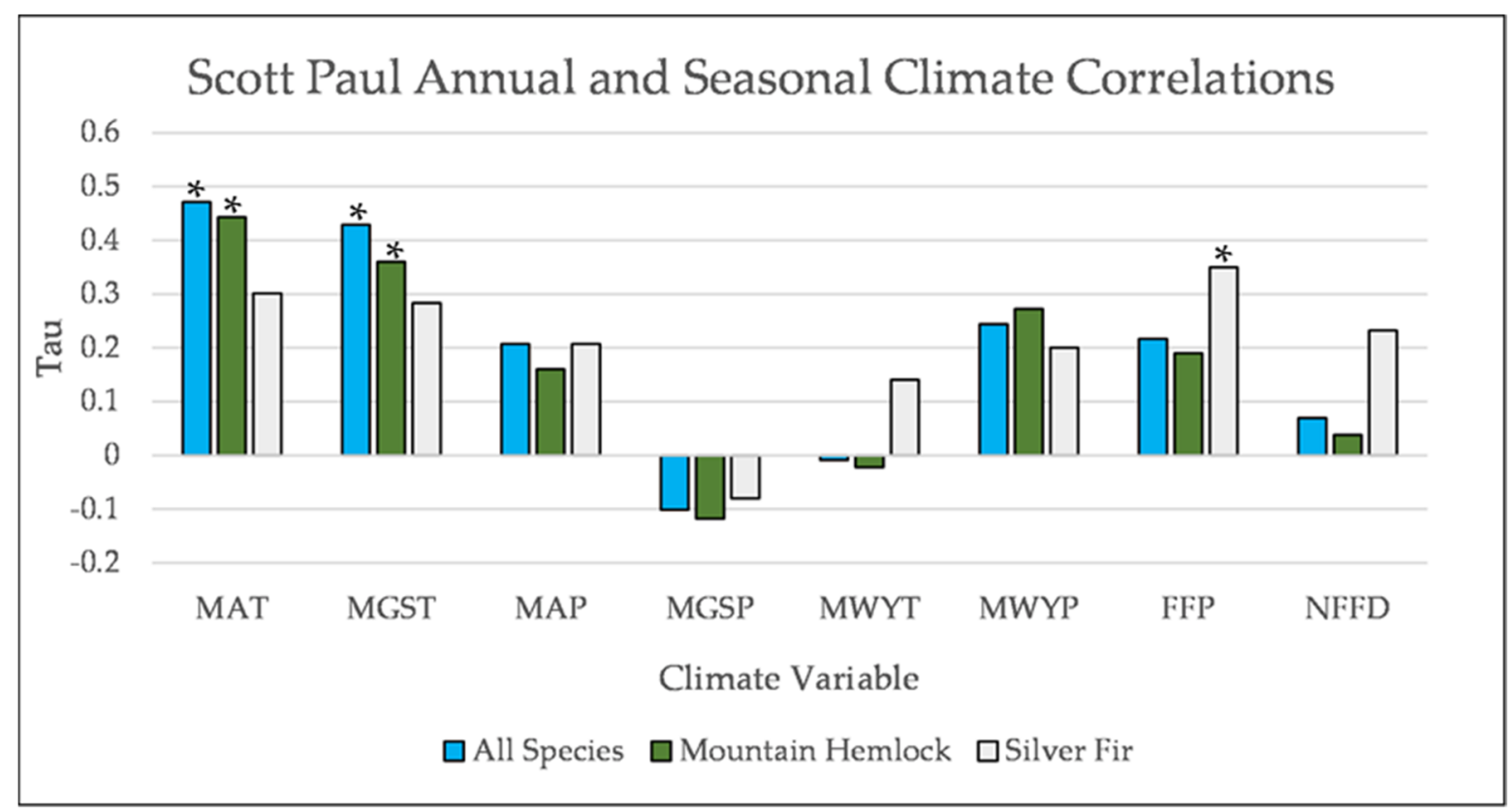

Figure A8. Partial Kendall's correlations between establishment and annual and seasonal climate variables at Scott Paul. * ${ }^{*}$-value < 0.05. Mean Annual Temperature (MAT), Mean Growing Season Temperature (MGST), Mean Annual Precipitation (MAP), Mean Growing Season Precipitation (MGSP), Mean Water Year Temperature (MWYT), Mean Water Year Precipitation (MWYP), Frost Free Period (FFP), and Number of Frost-Free Days (NFFD).

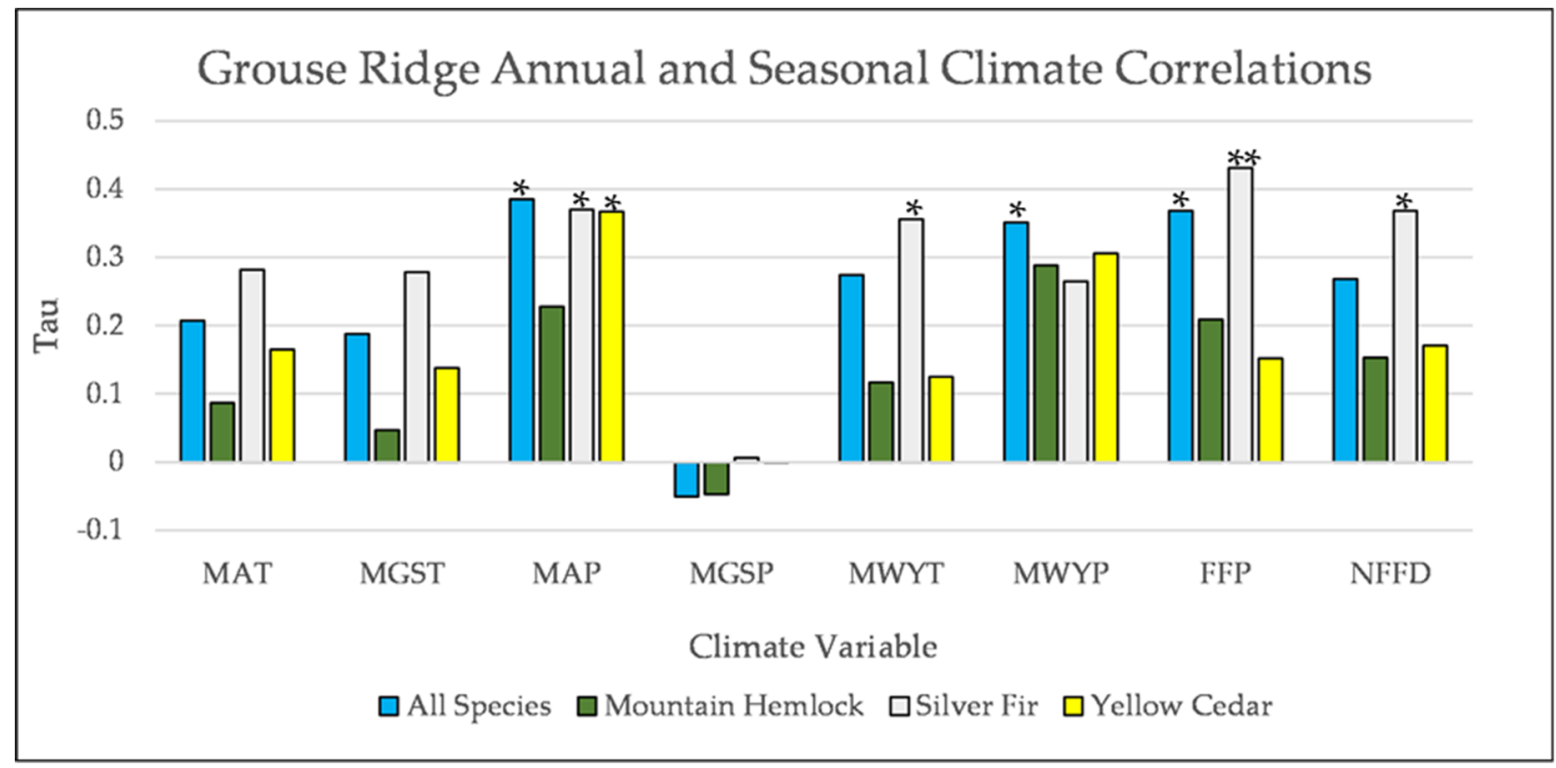

Figure A9. Partial Kendall's correlations between establishment and annual and seasonal climate variables at Grouse Ridge. ${ }^{*}=p$-value $<0.05,{ }^{* *}=p$-value $<0.01$. Mean Annual Temperature (MAT), Mean Growing Season Temperature (MGST), Mean Annual Precipitation (MAP), Mean Growing Season Precipitation (MGSP), Mean Water Year Temperature (MWYT), Mean Water Year Precipitation (MWYP), Frost Free Period (FFP), and Number of Frost-Free Days (NFFD). 


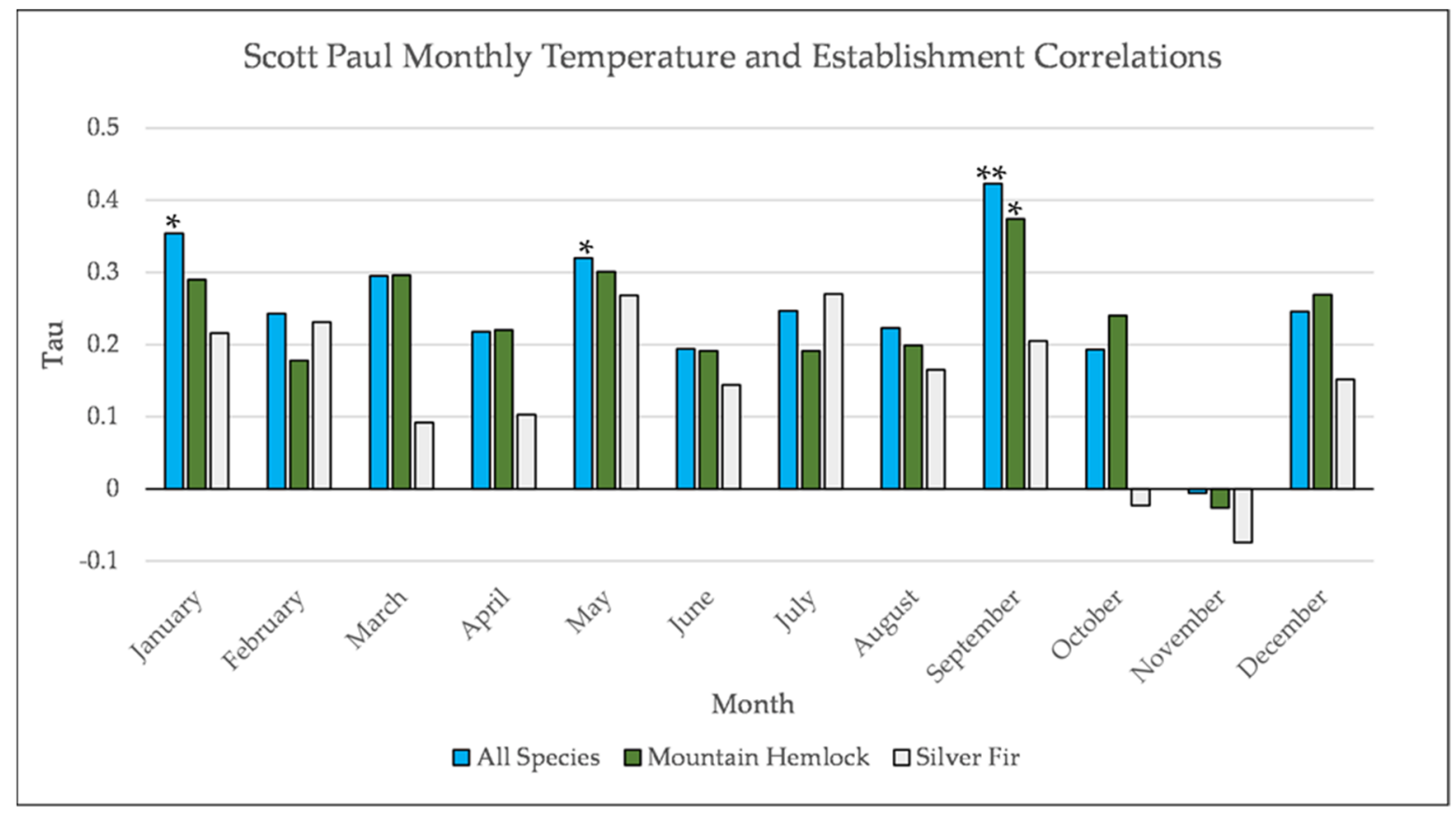

Figure A10. Partial Kendall's correlation between mean monthly temperature and establishment at the Scott Paul site. * $=p$-value $<0.05,{ }^{* *}=p$-value $<0.01$.

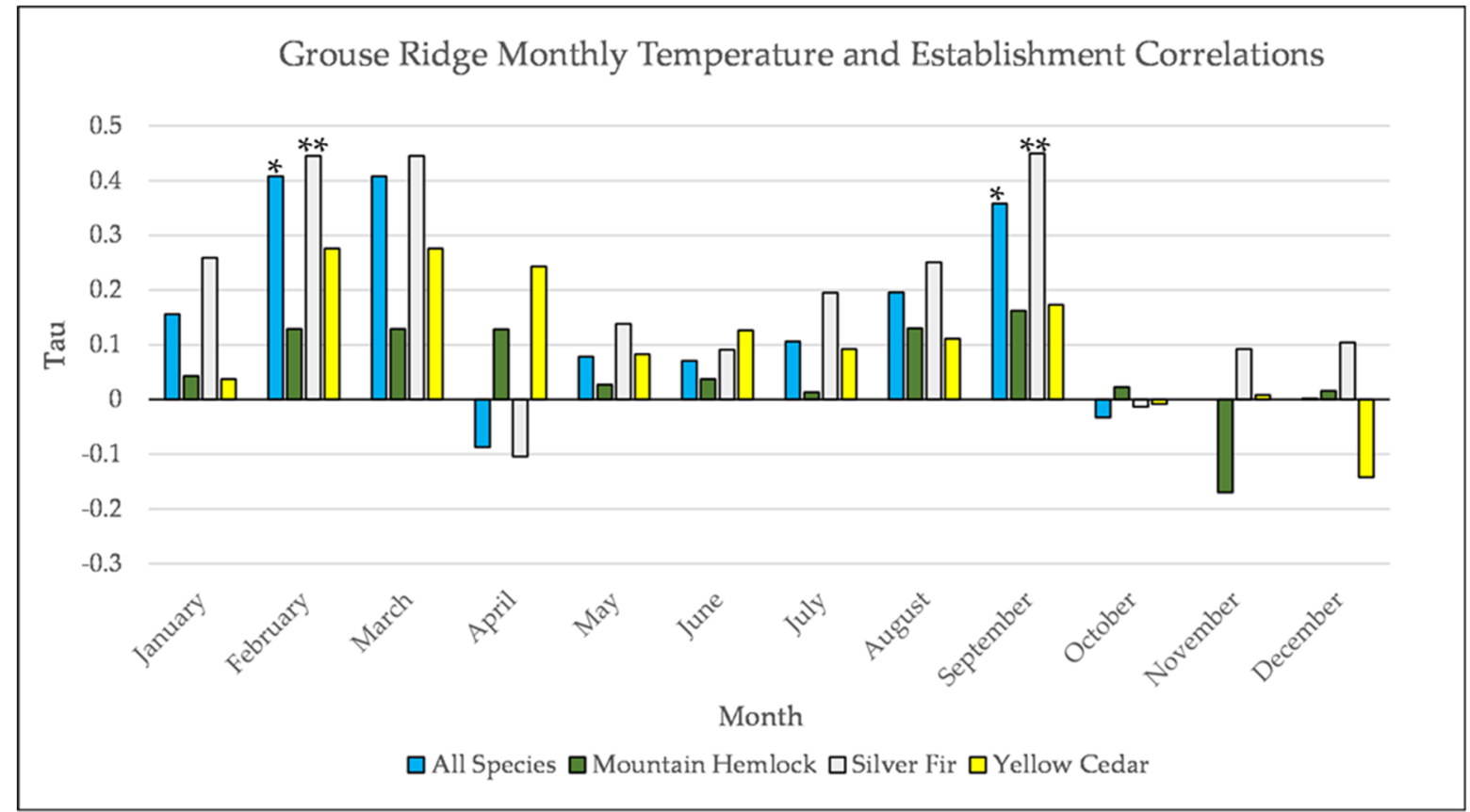

Figure A11. Partial Kendall's correlation between mean monthly temperature and establishment at the Grouse Ridge site ${ }^{*}=p$-value $<0.05,{ }^{* *}=p$-value $<0.01$. 


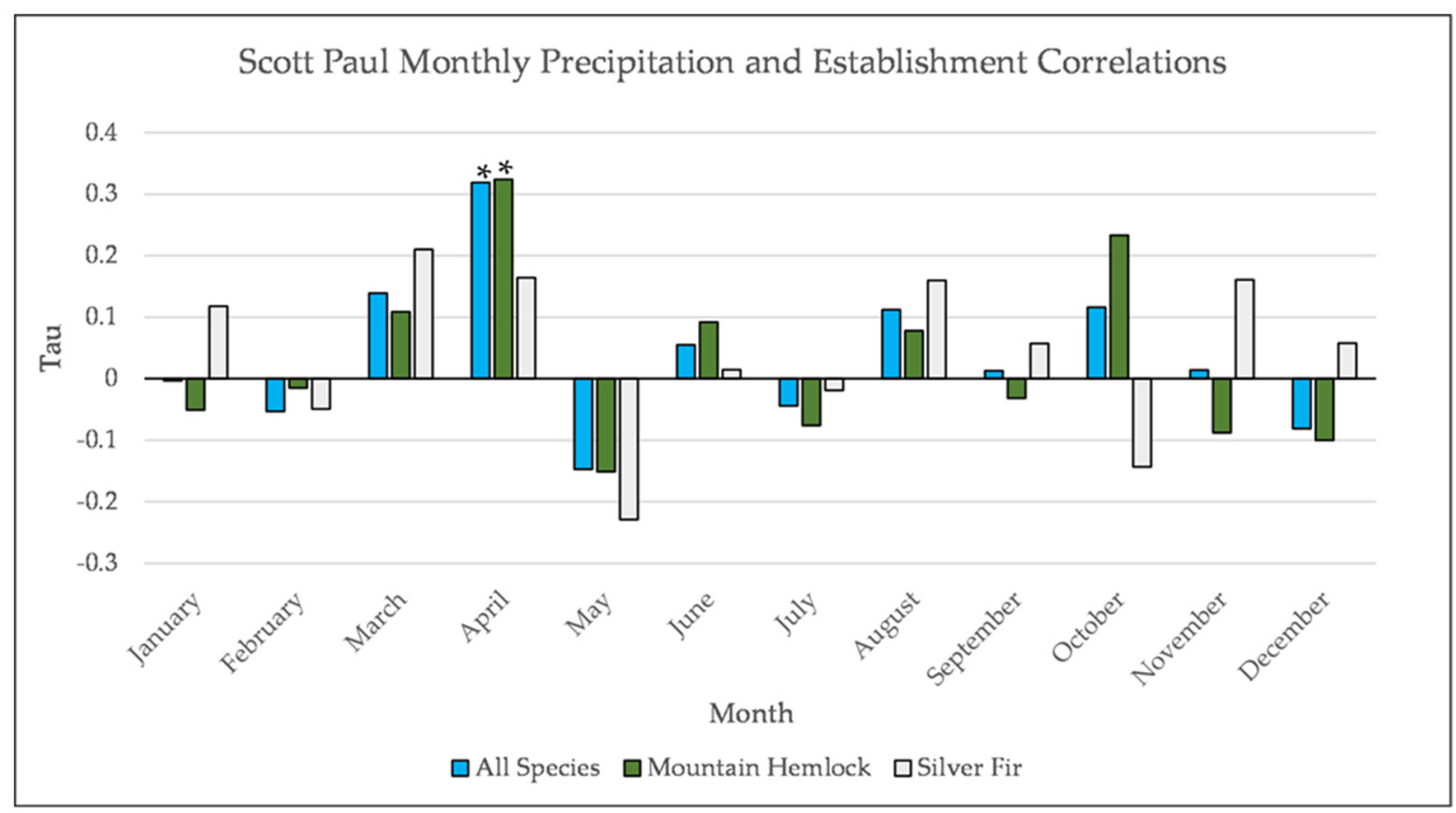

Figure A12. Partial Kendall's correlation between mean monthly precipitation and establishment at the Scott Paul site. $* p$-value $<0.05$.

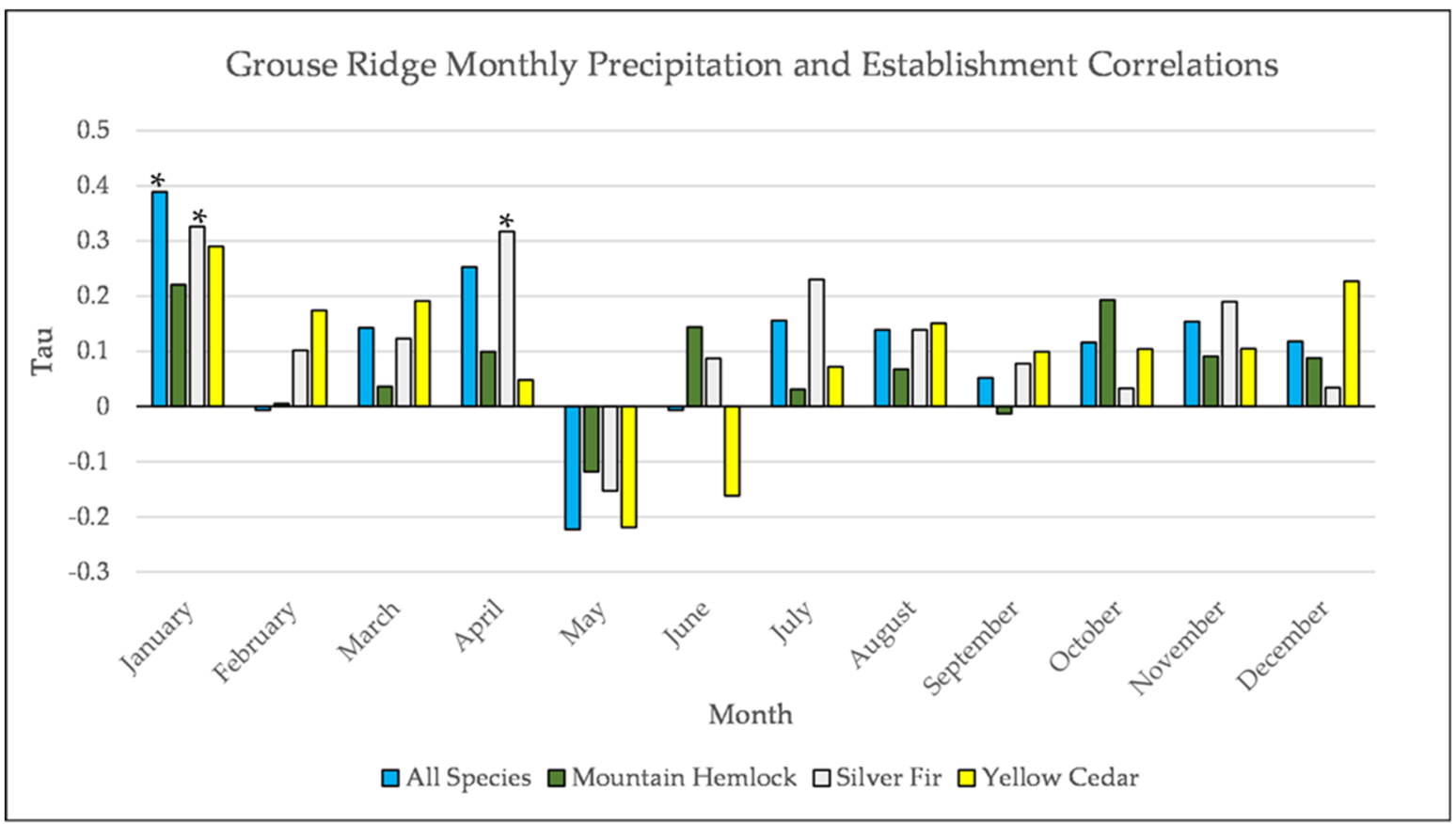

Figure A13. Partial Kendall's correlation between mean monthly precipitation and establishment at the Grouse Ridge site. $* p$-value $<0.05$. 


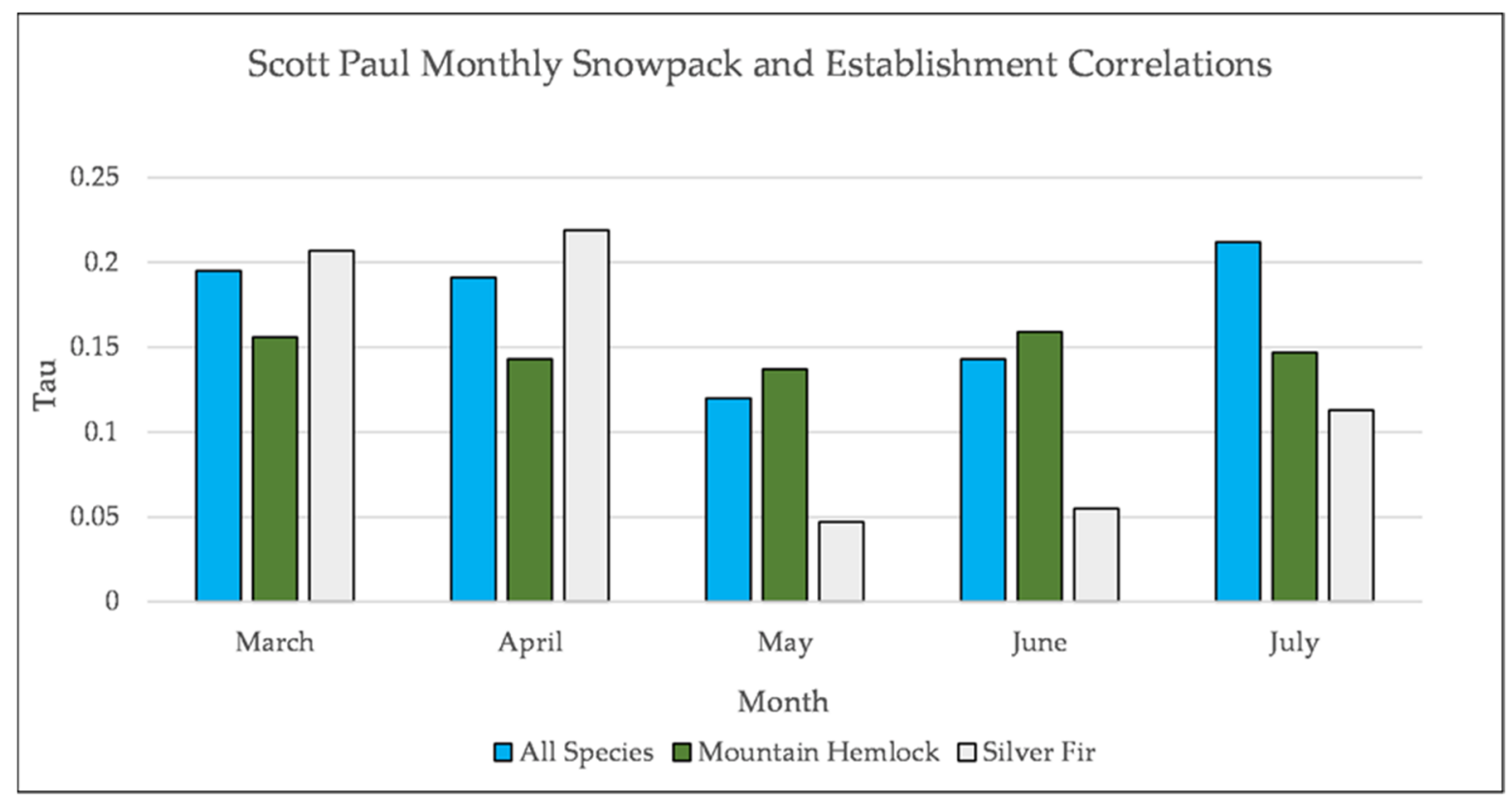

Figure A14. Partial Kendall's correlation controlled for temperature between mean monthly snowpack and establishment at Scott Paul. None of these correlations are significant.

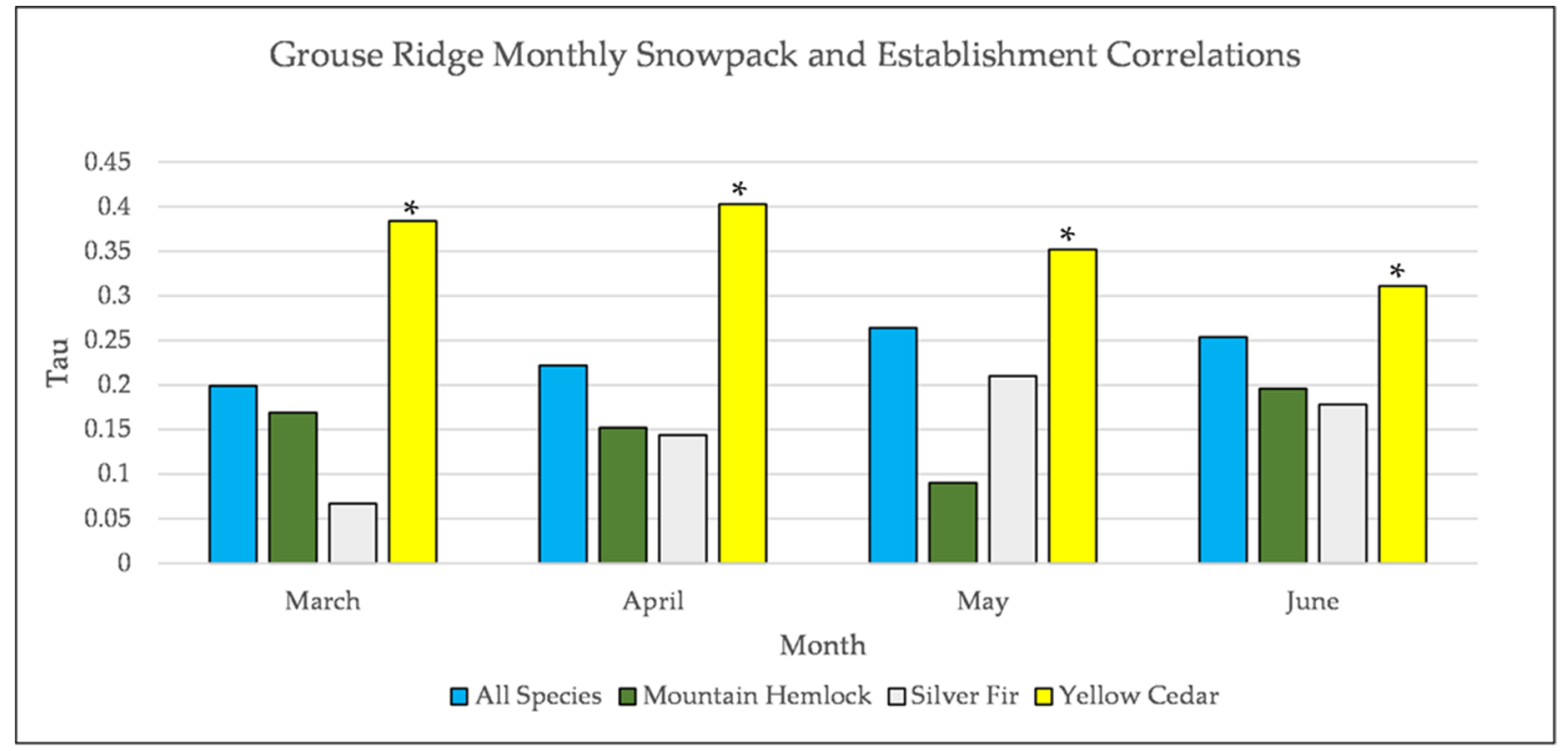

Figure A15. Partial Kendall's correlation controlled for temperature between snowpack and establishment at Grouse Ridge. * $=p$-value $<0.05$. July is not included for snowpack at Grouse Ridge because there is rarely any snowpack at Grouse Ridge in July. 


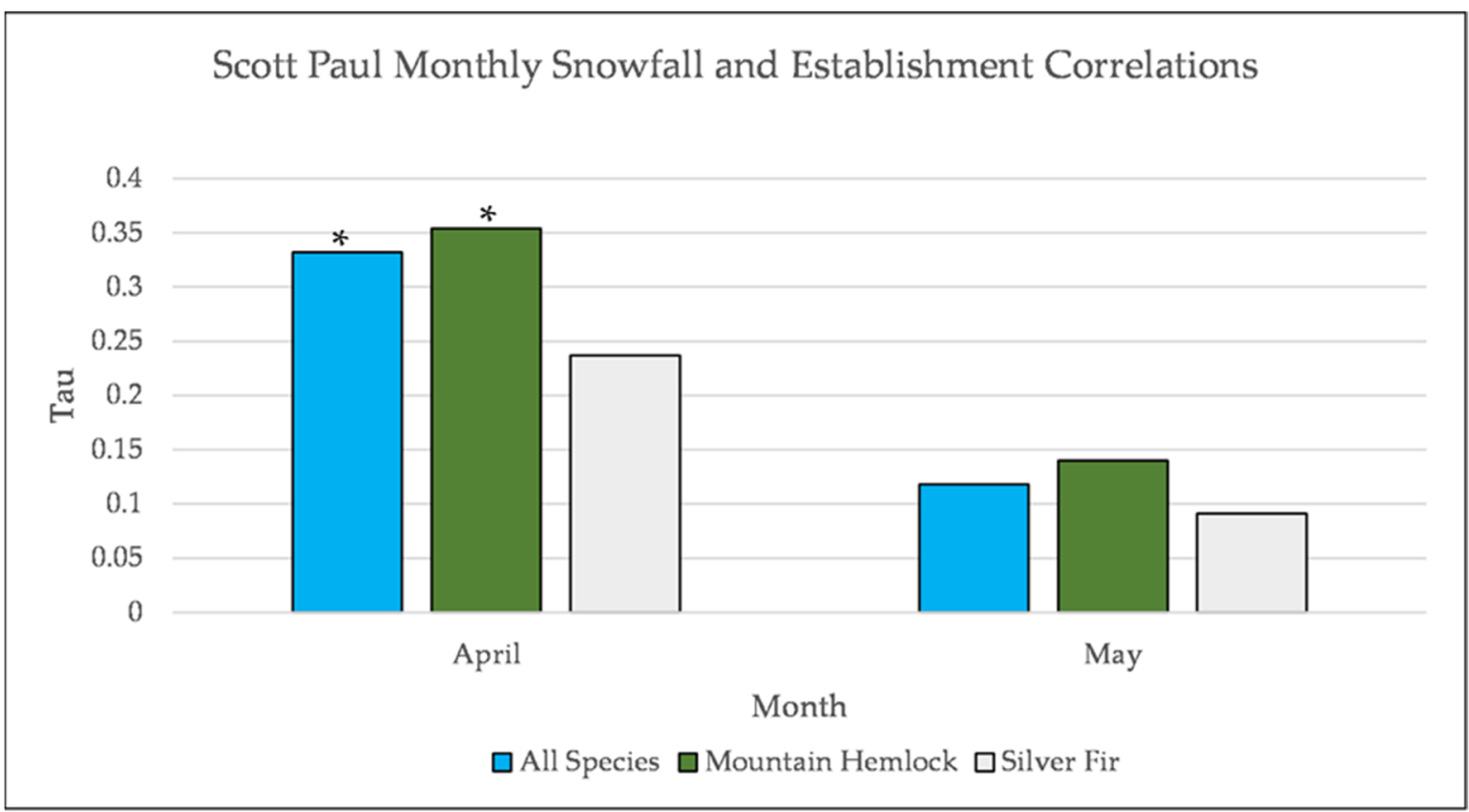

Figure A16. Partial Kendall's correlation controlled for temperature between snowfall and establishment at Scott Paul. * $=p$-value $<0.05$.

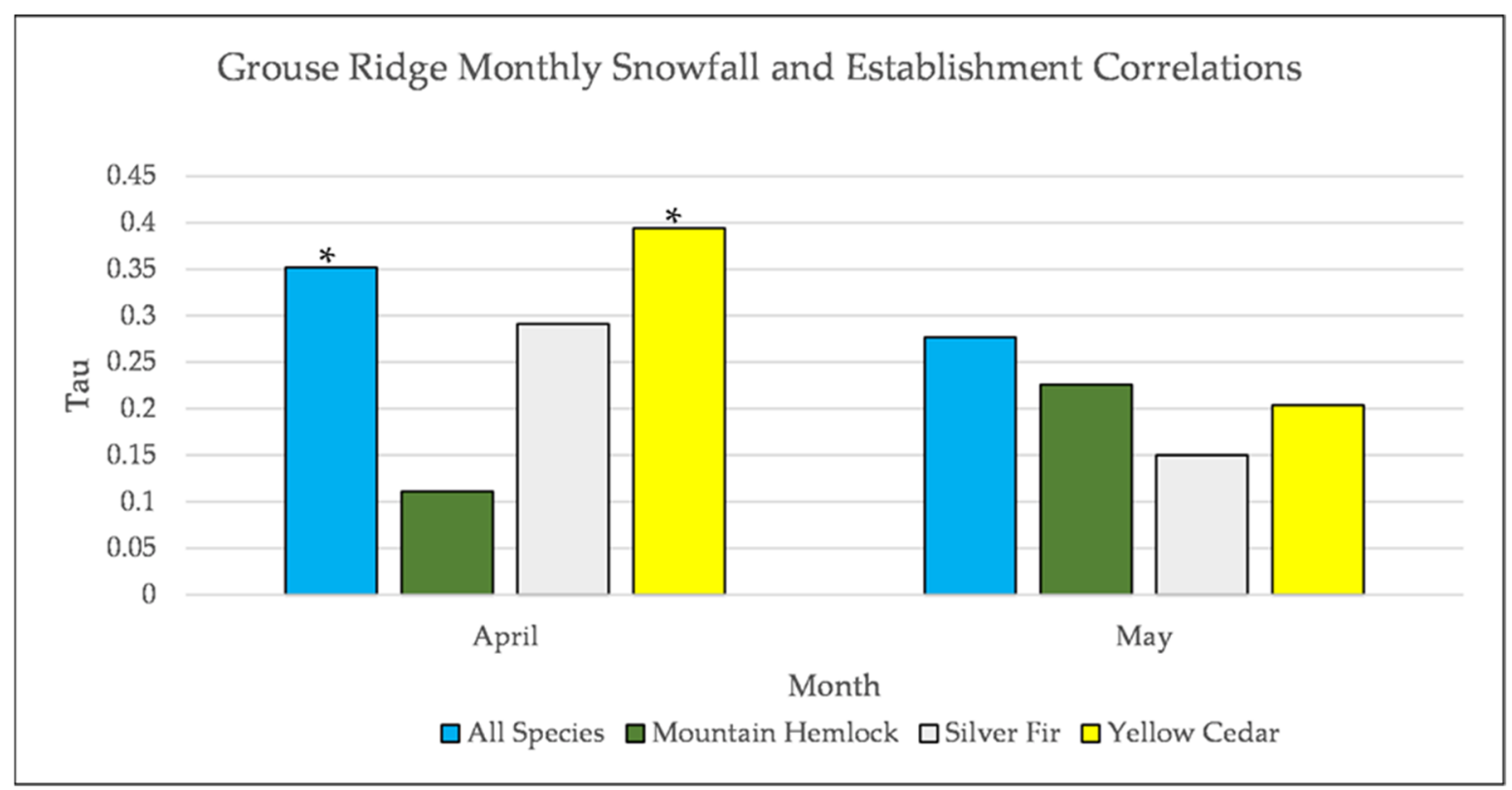

Figure A17. Partial Kendall's correlation controlled for temperature between snowfall and establishment at Grouse Ridge. $* p$-value $<0.05$. 


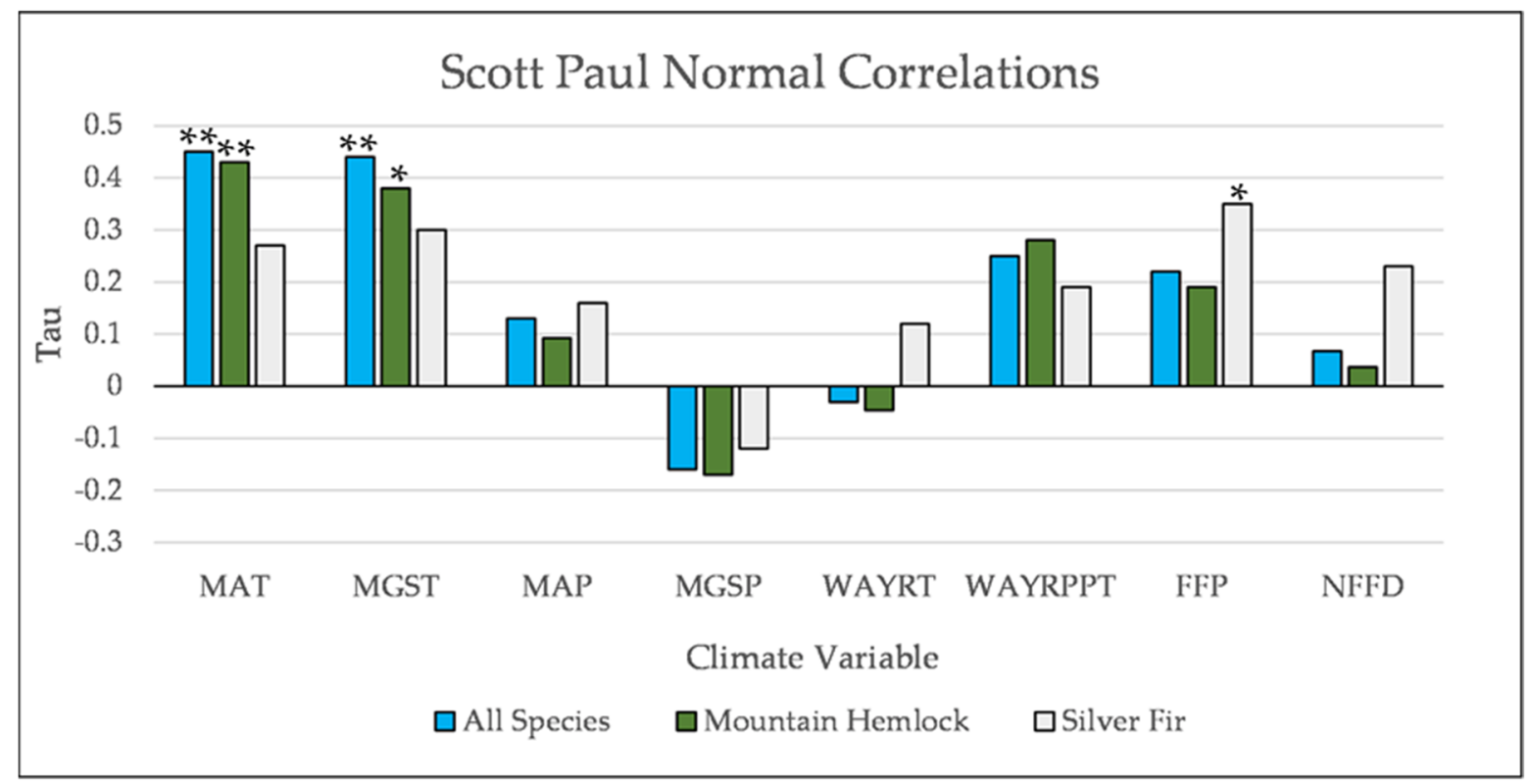

Figure A18. Normal Kendall's correlations between establishment and annual and seasonal climate variables at Scott Paul. * $=p$-value $<0.05,{ }^{* *}=p$-value $<0.01$. Mean Annual Temperature (MAT), Mean Growing Season Temperature (MGST), Mean Annual Precipitation (MAP), Mean Growing Season Precipitation (MGSP), Mean Water Year Temperature (MWYT), Mean Water Year Precipitation (MWYP), Frost Free Period (FFP), and Number of Frost Free Days (NFFD).

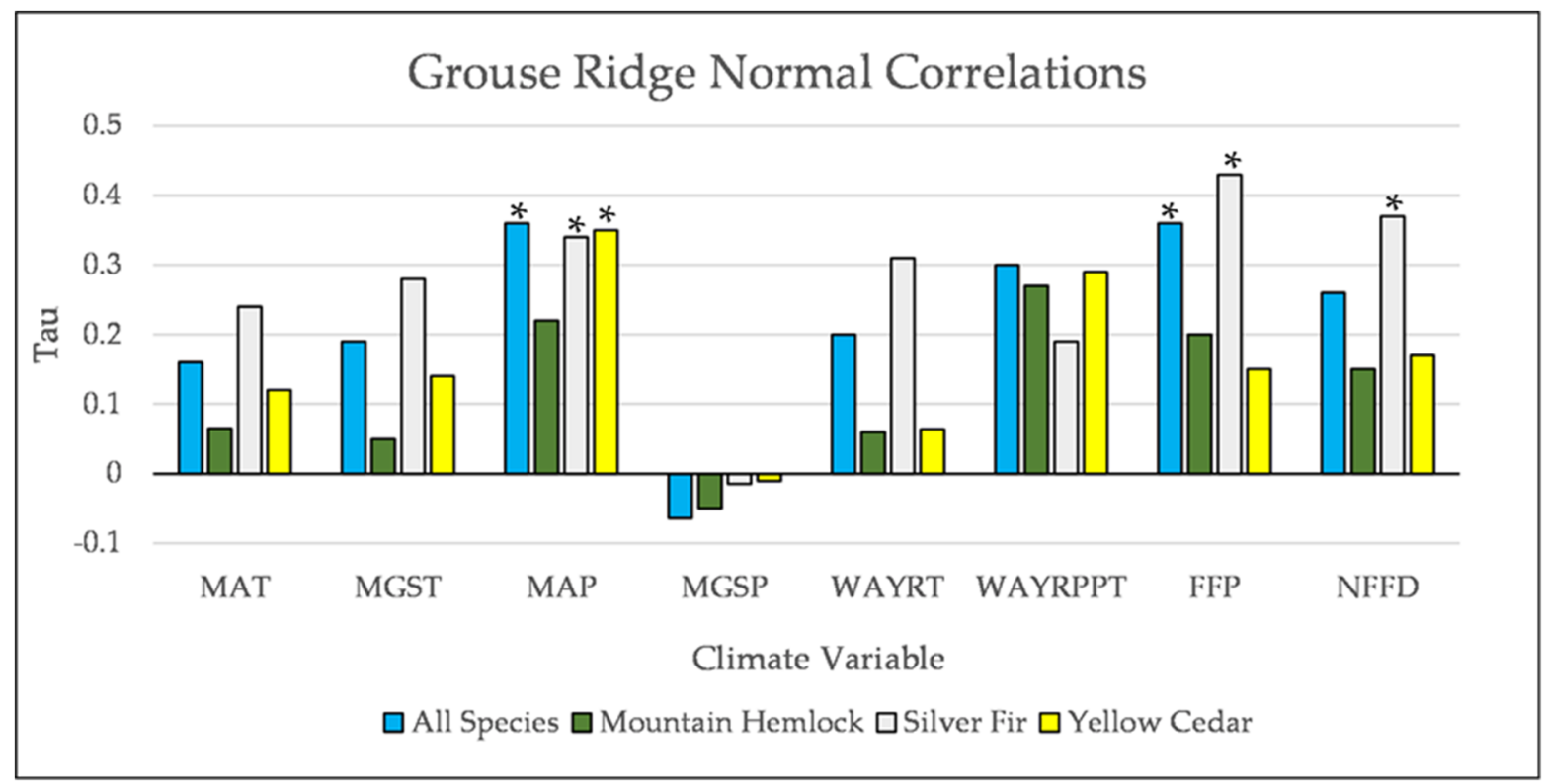

Figure A19. Normal Kendall's correlations between establishment and annual and seasonal climate variables at Grouse Ridge. ${ }^{*}=p$-value $<0.05$. Mean Annual Temperature (MAT), Mean Growing Season Temperature (MGST), Mean Annual Precipitation (MAP), Mean Growing Season Precipitation (MGSP), Mean Water Year Temperature (MWYT), Mean Water Year Precipitation (MWYP), Frost Free Period (FFP), and Number of Frost Free Days (NFFD). 


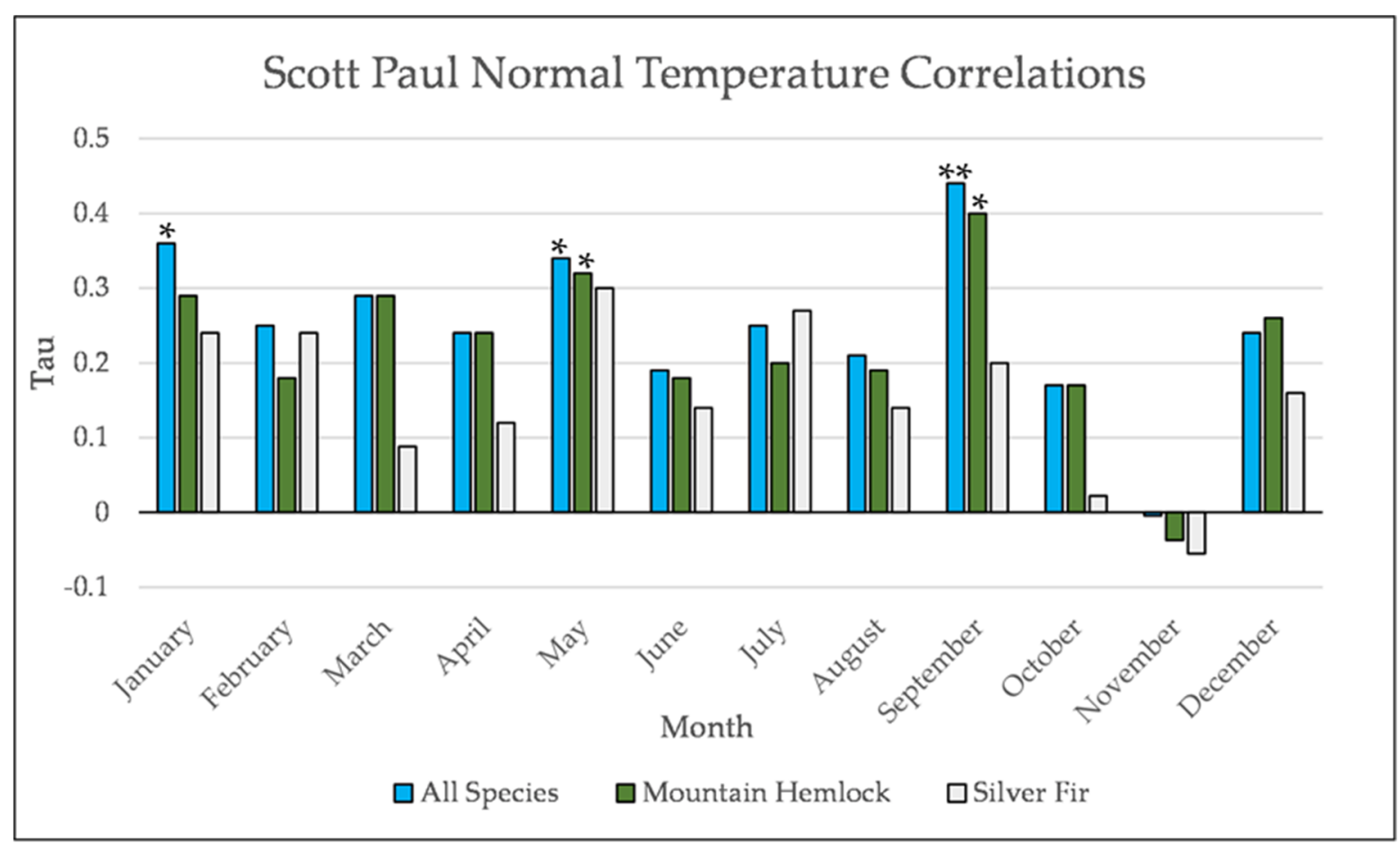

Figure A20. Normal Kendall's correlation between mean monthly temperature and establishment at the Scott Paul site. $*=p$-value $<0.05,{ }^{* *}=p$-value $<0.01$.

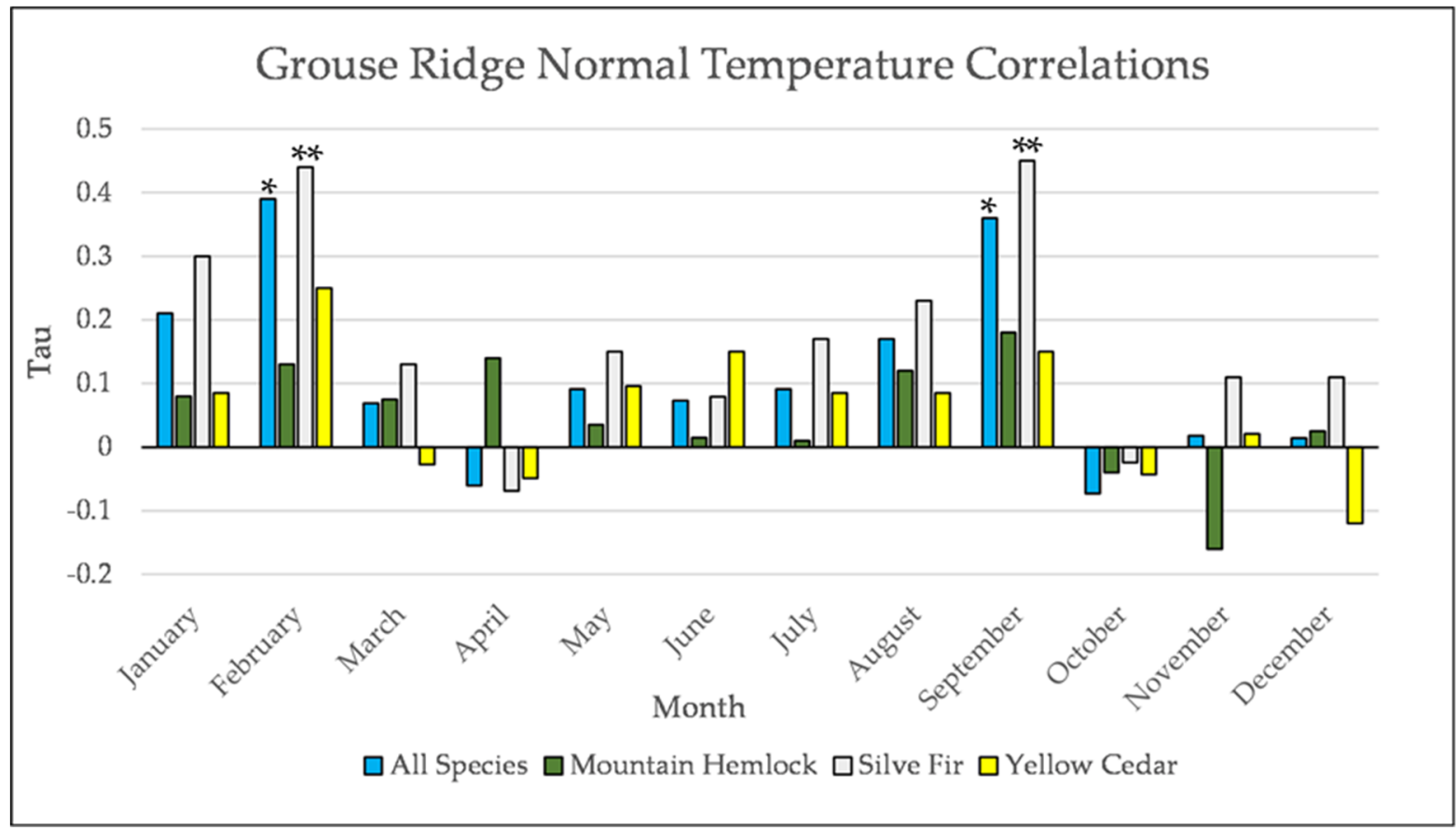

Figure A21. Normal Kendall's correlation between mean monthly temperature and establishment at the Grouse Ridge site ${ }^{*}=p$-value $<0.05,{ }^{* *}=p$-value $<0.01$. 


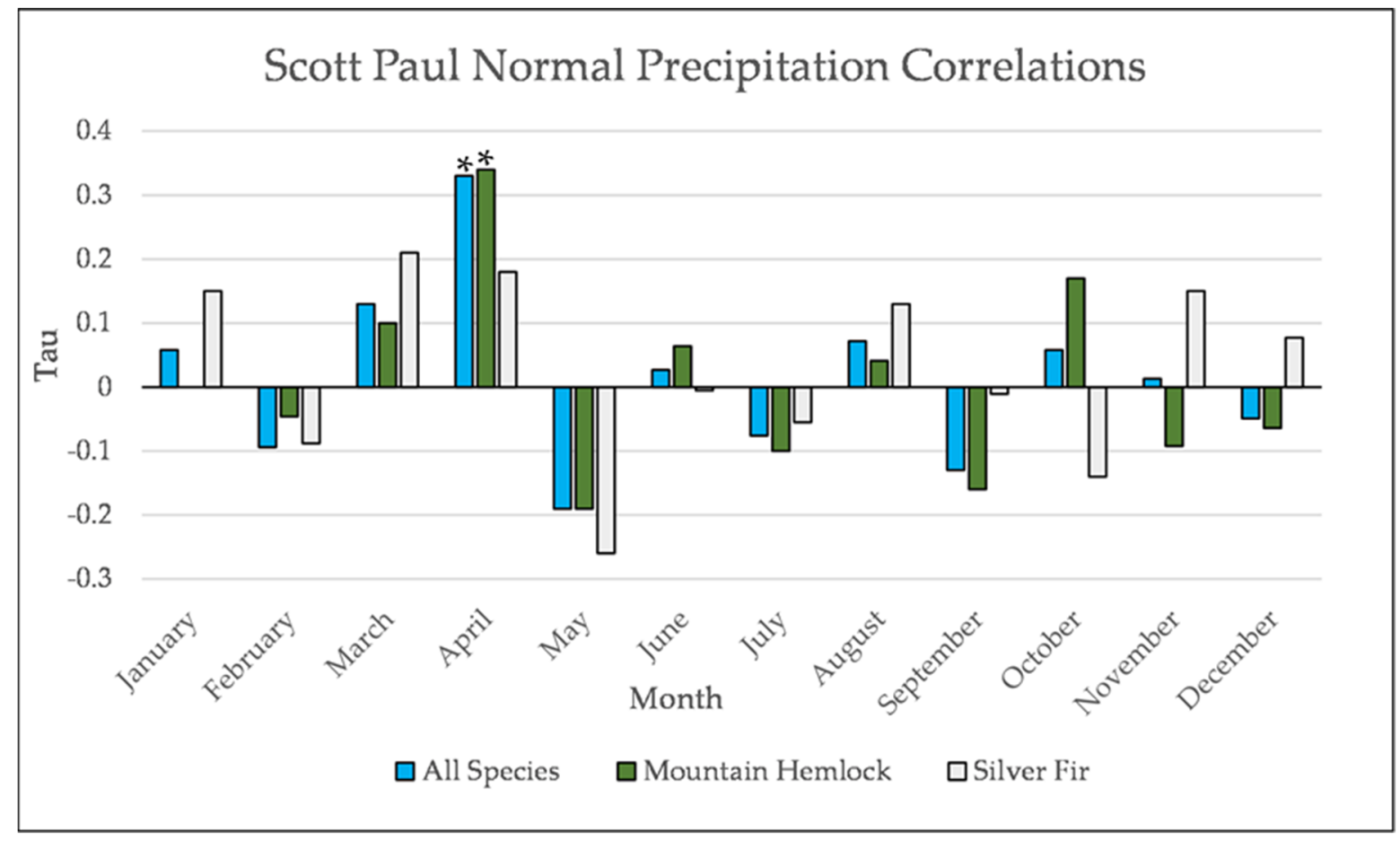

Figure A22. Normal Kendall's correlation between mean monthly precipitation and establishment at the Scott Paul site. $* p$-value $<0.05$.

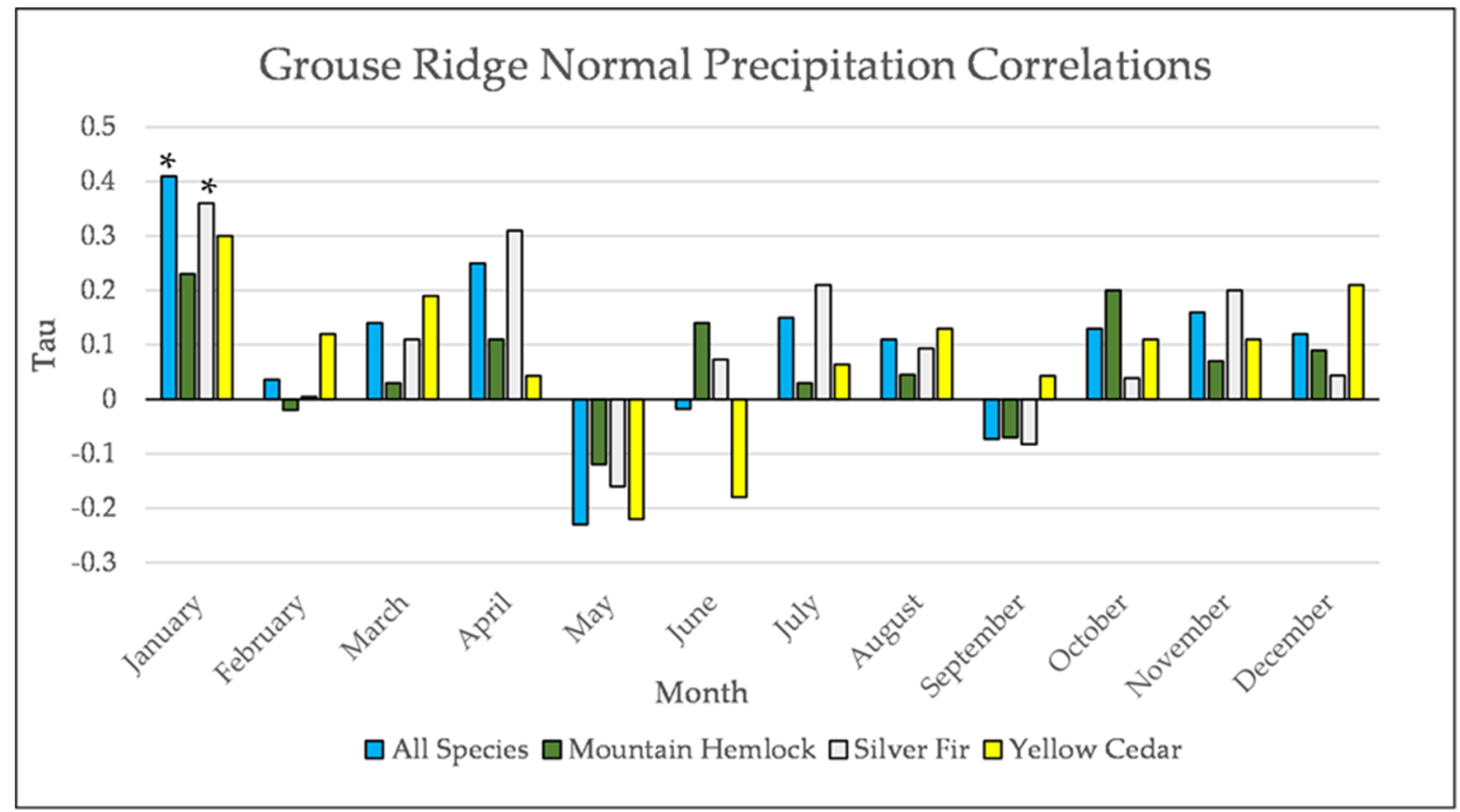

Figure A23. Normal Kendall's correlation between mean monthly precipitation and establishment at the Grouse Ridge site. $*=p$-value $<0.05$. 


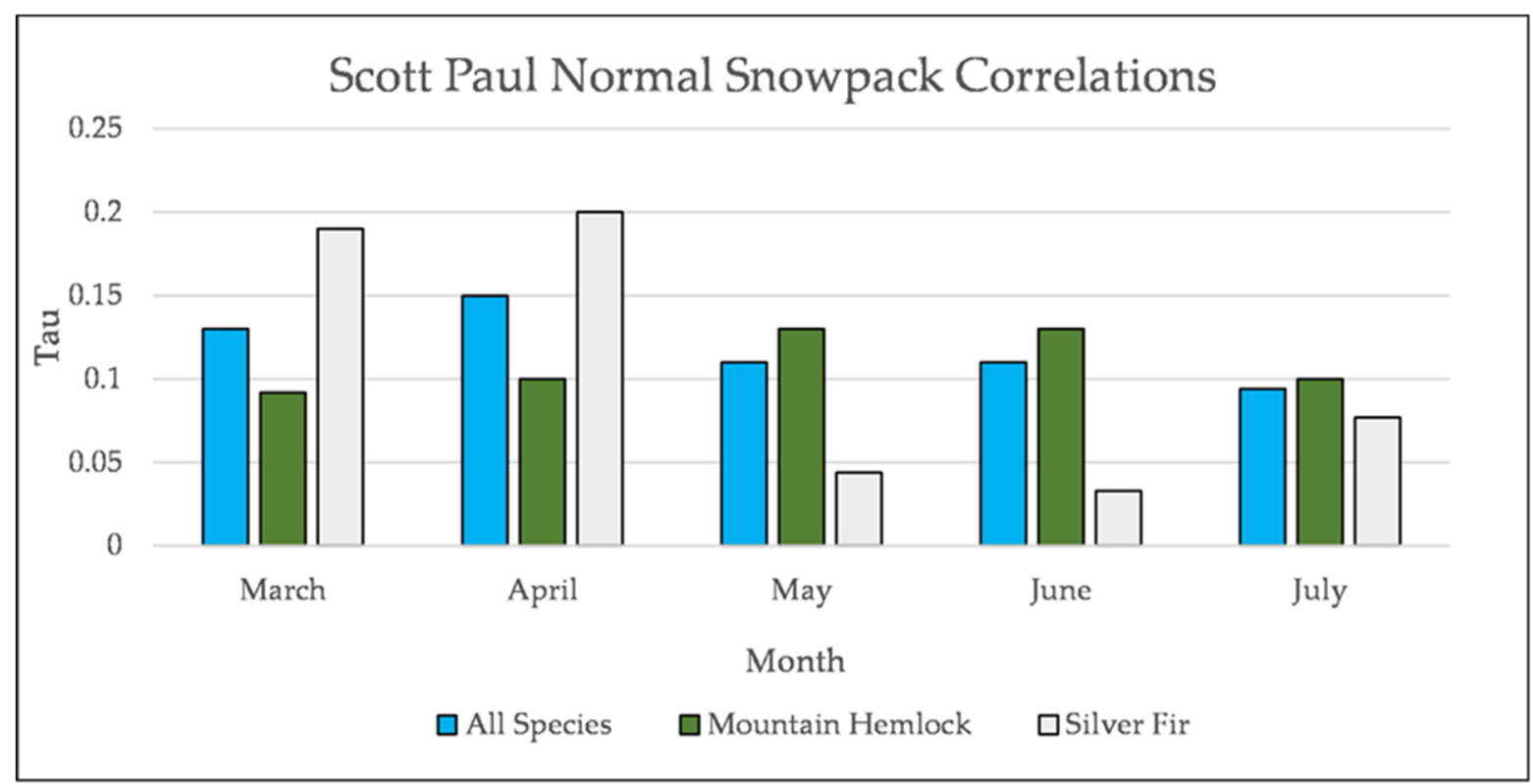

Figure A24. Normal Kendall's correlation controlled for temperature between mean monthly snowpack and establishment at Scott Paul. None of these correlations are significant.

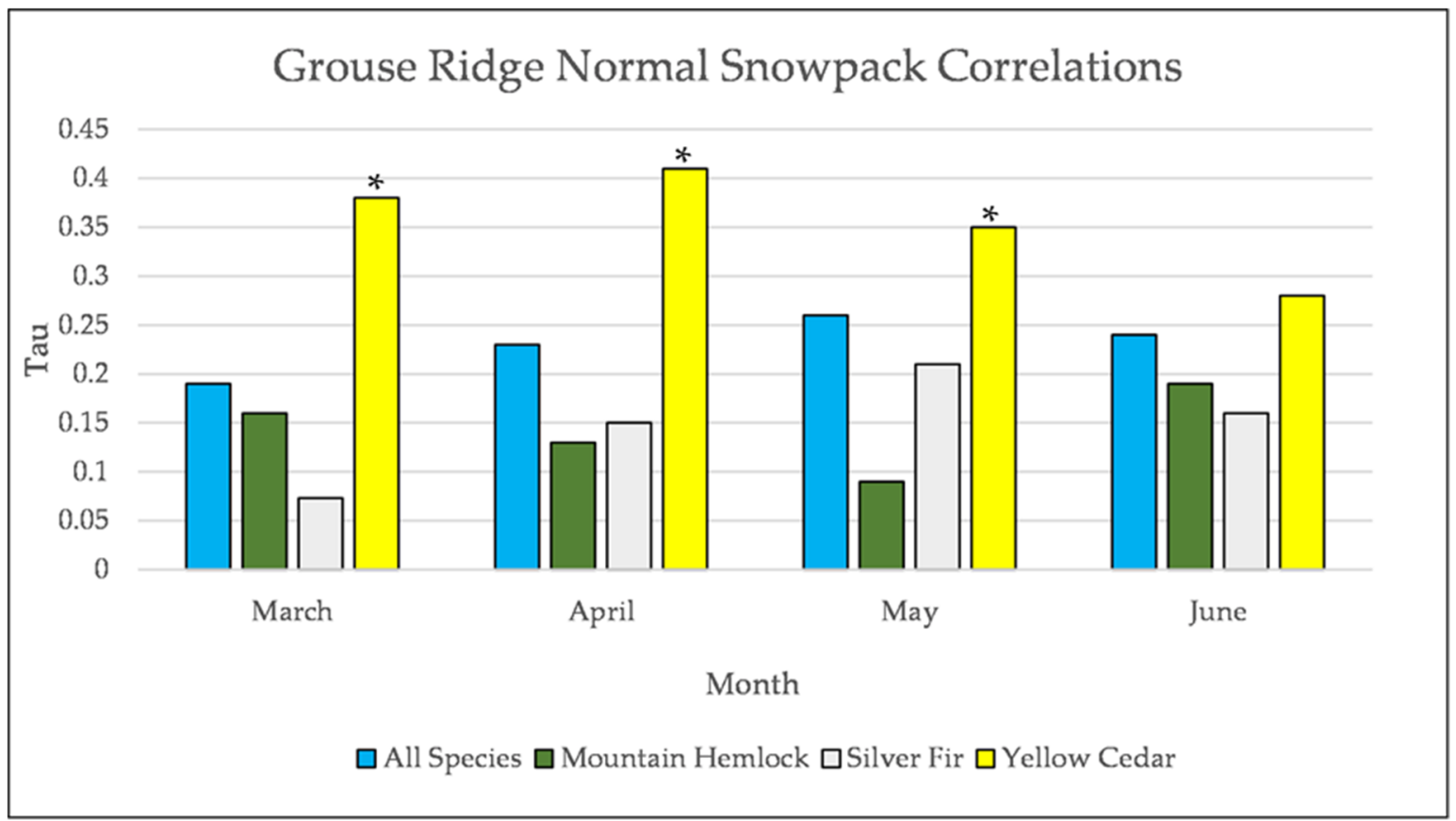

Figure A25. Normal Kendall's correlation controlled for temperature between snowpack and establishment at Grouse Ridge. ${ }^{*}=p$-value $<0.05$. July is not included for snowpack at Grouse Ridge because there is rarely any snowpack at Grouse Ridge in July. 


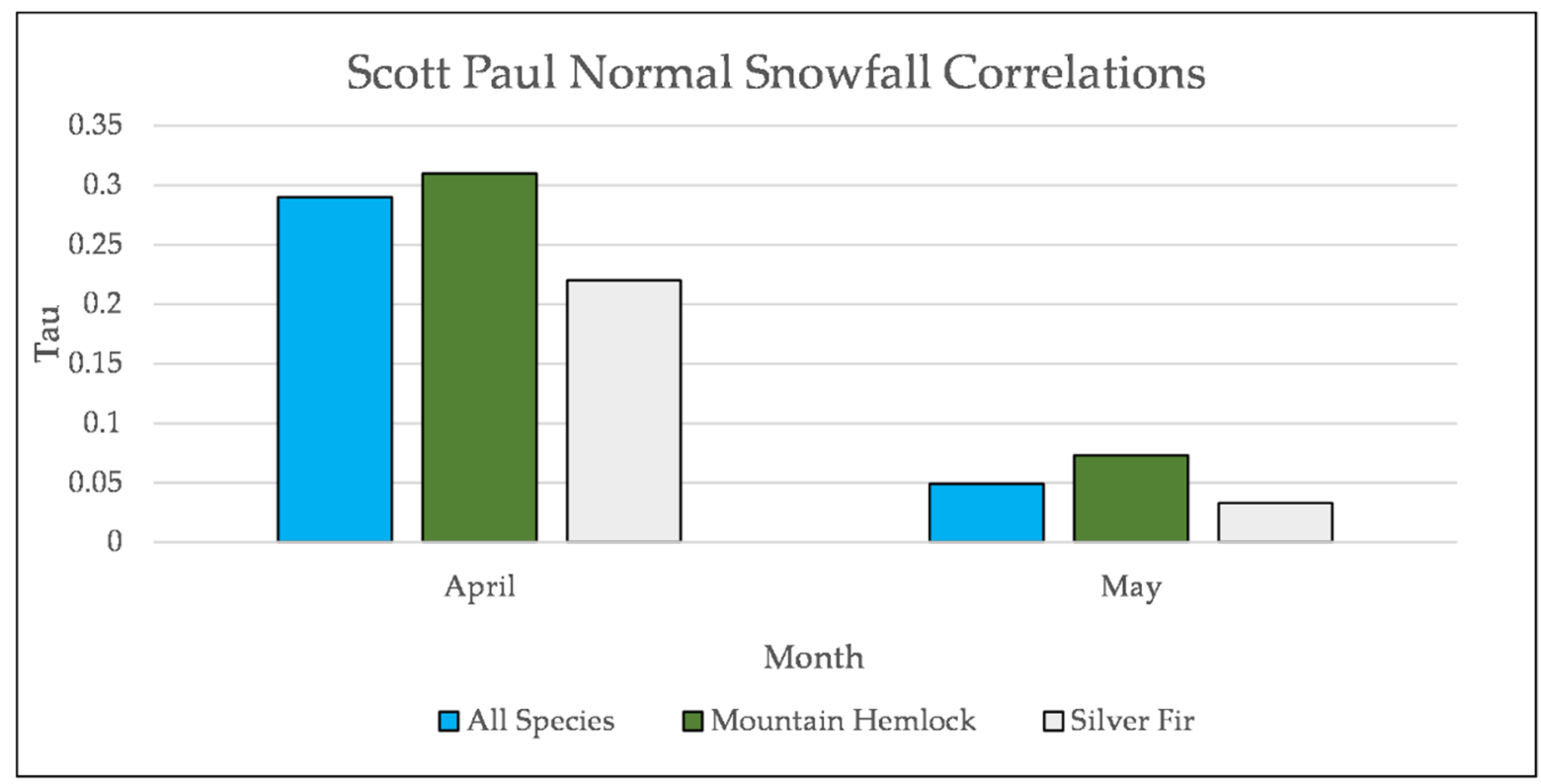

Figure A26. Normal Kendall's correlation controlled for temperature between snowfall and establishment at Scott Paul. $* p$-value $<0.05$.

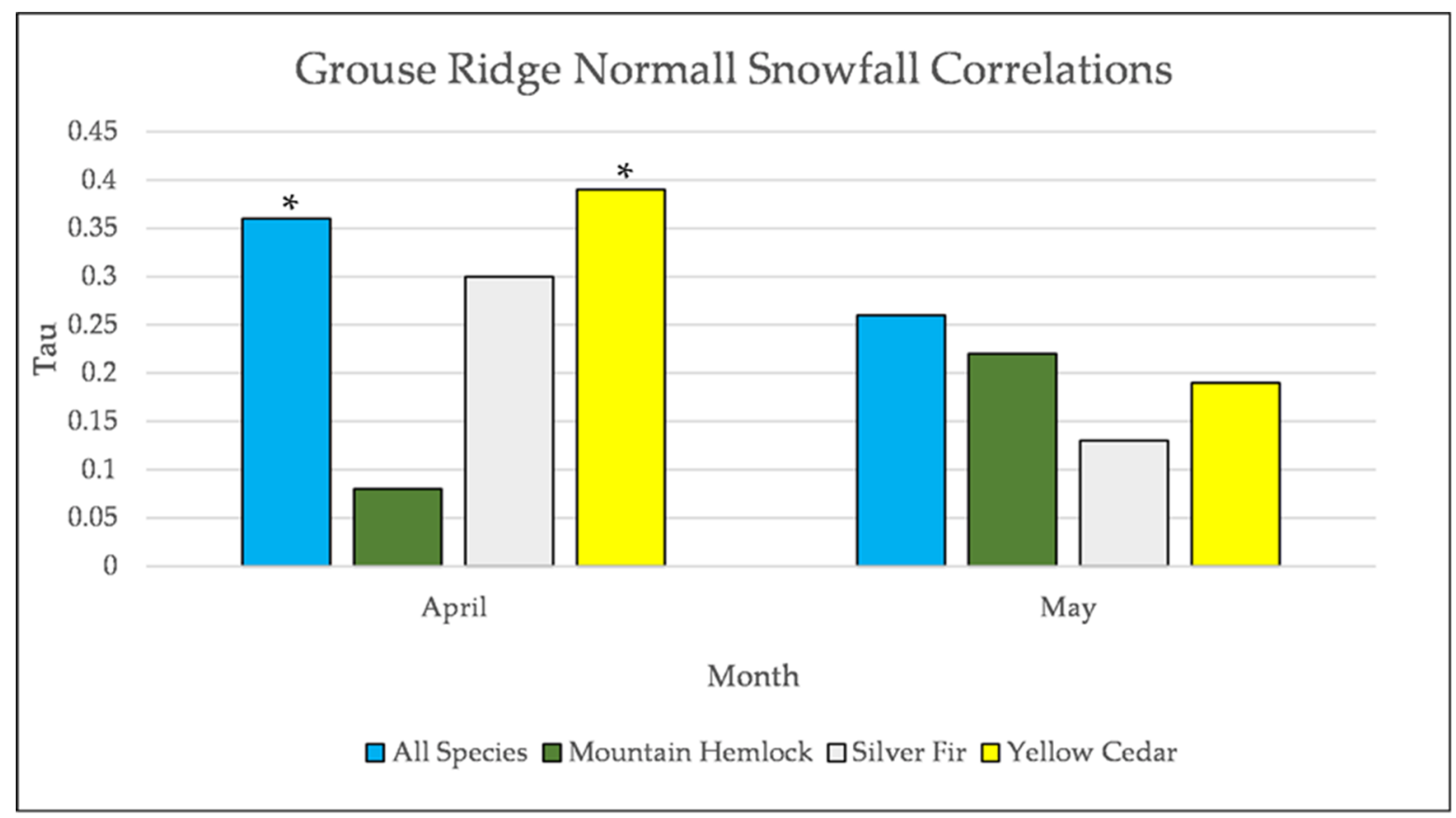

Figure A27. Normal Kendall's correlation controlled for temperature between snowfall and establishment at Grouse Ridge. * $=p$-value $<0.05$.

\section{References}

1. Lubetkin, K.C.; Westerling, A.L.; Kueppers, L.M. Climate and landscape drive the pace and pattern of conifer encroachment in subalpine meadows. Ecol. Appl. 2017, 27, 1-12. [CrossRef] [PubMed]

2. Armitage, K.B. Climate change and the conservation of marmots. Nat. Sci. 2013, 5, 36-43. [CrossRef]

3. Erb, L.P.; Ray, C.; Guralnick, R. On the generality of a climate-mediated shift in the distribution of the American pika (Ochotona princeps). Ecology 2011, 92, 1730-1735. [CrossRef] [PubMed]

4. Clow, D.W.; Schrott, L.; Webb, R.; Campbell, D.H.; Torizzo, A.; Dornblaser, M. Ground watter occurrence and contributions to streamflow in an alpine catchment, Colorado Front Range. Ground Water 2003, 41, 937-950. [CrossRef]

5. Roland, J.; Matter, S.F. Encroaching forests decouple alpine butterfly population dynamics. Proc. Natl. Acad. Sci. USA 2007, 104, 13702-13704. [CrossRef] 
6. Malanson, G.P.; Butler, D.R.; Fagre, D.B.; Walsh, S.J.; Tomback, D.F.; Daniels, L.D.; Resler, L.M.; Smith, W.K.; Weiss, D.J.; Peterson, D.L.; et al. Alpine Treeline of Western North America: Linking Organism-To-Landscape Dynamics. Phys. Geogr. 2007, 28, 378-396. [CrossRef]

7. Mantua, N.; Tohver, I.; Hamlet, A. Climate change impacts on streamflow extremes and summertime stream temperature and their possible consequences for freshwater salmon habitat in Washington State. Clim. Chang. 2010, 102, 187-223. [CrossRef]

8. Wells, A.G.; Wallin, D.O.; Rice, C.G.; Chang, W.-Y. GPS Bias Correction and Habitat Selection by Mountain Goats. Remote Sens. 2011, 3, 435-459. [CrossRef]

9. Whitesides, C.J.; Butler, D.R. Adequacies and deficiencies of alpine and subalpine treeline studies in the national parks of the western USA. Prog. Phys. Geogr. Earth Environ. 2011, 35, 19-42. [CrossRef]

10. Franklin, J.F.; Moir, W.H.; Douglas, G.W.; Wiberg, C. Invasion of subalpine meadows by trees in the Cascade Range, Washington and Oregon. Arct. Alp. Res. 1971, 3, 215-224. [CrossRef]

11. Woodward, A.; Schreiner, E.G.; Silsbee, D.G. Climate, geography, and tree establishment in subalpine meadows of the Olympic Mountains, Washington, U.S.A. Arct. Alp. Res. 1995, 27, 217-225. [CrossRef]

12. Rochefort, R.M.; Peterson, D.L. Temproal and spatial distribution of trees in subalpine meadows of Mount Rainer National Park, Washington, U.S.A. Arct. Alp. Res. 1996, 28, 52-59. [CrossRef]

13. Miller, E.A.; Halpern, C.B. Effects of environment and grazing disturbance on tree establishment in meadows of the central Cascade Range, Oregon, USA. J. Veg. Sci. 1998, 9, 265-282. [CrossRef]

14. Laroque, C.P.; Lewis, D.H.; Smith, D.J. Treeline dynamics on Southern Vancouver Island, British Columbia. West. Geogr. 2000, 10, 43-63.

15. Flower, A.; Bookout, B.; Hagedorn, B.; Hankin, L.; Lovseth, J.; Smith, L.; Whelan, A. Muscling into Meadows: A Preliminary Dendrochronological Analysis of Recent Conifer Encroachment in Mount Rainier's Subalpine Meadows. Yearb. Assoc. Pac. Coast Geogr. 2017, 79, 115-133. [CrossRef]

16. Zald, H.S.J.; Spies, T.A.; Huso, M.; Gatziolis, D. Climatic, landform, microtopographic, and overstory canopy controls of tree invasion in a subalpine meadow landscape, Oregon Cascades, USA. Landsc. Ecol 2012, 27, 1197-1212. [CrossRef]

17. Osborn, G.; Menounos, B.; Ryane, C.; Riedel, J.; Clague, J.J.; Koch, J.; Clark, D.; Scott, K.; Davis, P.T. Latest Pleistocene and Holocene glacier fluctuations on Mount Baker, Washington. Quat. Sci. Rev. 2012, 49, 33-51. [CrossRef]

18. Peel, M.C.; Finlayson, B.L.; McMahon, T.A. Updated world map of the Köppen-Geiger climate classification. Hydrol. Earth Syst. Sci. 2007, 11, 1633-1644. [CrossRef]

19. Leffler, R.J.; Horvitz, A.; Downs, R.; Changery, M.; Redmond, K.T.; Taylor, G. Evaluation of a national seasonal snowfall record at the Mount Baker, Washington, Ski Area. Natl. Weather Dig. 2001, 25, 15-20.

20. Klinka, K.; Wang, Q.; Kayahara, G.J.; Carter, R.E.; Blackwell, B.A. Light-growth response relationships in Pacific silver fir (Abies amabilis) and subalpine fir (Abies lasiocarpa). Can. J. Bot. 1992, 70, 1919-1930. [CrossRef]

21. Laroque, C.P.; Smith, D.J. Tree-ring analysis of yellow-cedar (Chamaecyparis nootkatensis) on Vancouver Island, British Columbia. Candian J. For. Res. 1999, 29, 115-123. [CrossRef]

22. Antos, J.A.; Zobel, D.B. Habitat relationships of Chamaecyparis nootkatensis in southern Washington, Oregon, and California. Can. J. Bot. 1986, 64, 1898-1909. [CrossRef]

23. Turner, N.J.; Deur, D.; Mellott, C.R. "Up on the Mountain”: Ethnobotanical Importance of Montane Site in Pacific Coastal North America. J. Ethnobiol. 2011, 31, 4-43. [CrossRef]

24. Urza, A.K.; Sibold, J.S. Nondestructive Aging of Postfire Seedlings for Four Conifer Species in Northwestern Montana. West. J. Appl. For. 2013, 28, 22-29. [CrossRef]

25. Yamaguchi, D.K. A simple method for cross-dating increment cores from living trees. Can. J. For. Res. 1991, 21, 414-416. [CrossRef]

26. Speer, J.H. Fundamentals of Tree-Ring Research; University of Arizona Press: Tucson, Arizona, 2010; ISBN 978-0-8165-2685-7.

27. Holmes, R.L. Computer-assisted quality control in tree-ring dating and measurement. Tree-Ring Bull. 1983, 43, 69-78.

28. Hamann, A.; Wang, T.; Spittlehouse, D.L.; Murdock, T.Q. A Comprehensive, High-Resolution Database of Historical and Projected Climate Surfaces for Western North America. Bull. Amer. Meteor. Soc. 2013, 94, 1307-1309. [CrossRef]

29. Daly, C.; Gipson, W.P.; Taylor, G.H.; Johnson, G.L.; Pasteris, P. A kowledge-based approach to the statistical mapping of climate. Clim. Res. 2002, 22, 99-113. [CrossRef]

30. Mitchell, T.D.; Jones, P.D. An improved method of constructing a database of monthly climate observations and associated high-resolution grids. Int. J. Climatol. 2005, 25, 693-712. [CrossRef]

31. Hostetler, S.W.; Alder, J.R. Implementation and evaluation of a monthly water balance model over the US on an $800 \mathrm{~m}$ grid: WATER BALANCE MODEL. Water Resour. Res. 2016, 52, 9600-9620. [CrossRef]

32. Whelan, P.; Bach, A.J. Retreating Glaciers, Incipient Soils, Emerging Forests: 100 Years of Landscape Change on Mount Baker, Washington, USA. Ann. Am. Assoc. Geogr. 2017, 107, 336-349. [CrossRef]

33. Morris, W.F.; Wood, D.M. The Role of Lupine in Succession on Mount St. Helens: Facilitation or Inhibition? Ecology 1989, 70, 697-703. [CrossRef]

34. Woodward, A.; Silsbee, D.G.; Schreiner, E.G.; Means, J.E. Influence of Climate on Radial Growth and Cone Production in Subalpine Fir (Abies Lasiocarpa) and Mountain Hemlock (Tusga mertensiana). Candian J. For. Res. 1994, 24, 1133-1143. [CrossRef]

35. Sloat, L.L.; Henderson, A.N.; Lamanna, C.; Enquist, B.J. The Effect of the Foresummer Drought on Carbon Exchange in Subalpine Meadows. Ecosystems 2015, 18, 533-545. [CrossRef] 
36. Germino, M.J.; Smith, W.K. Sky exposure, crown architecture, and low-temperature photoinhibition in conifer seedlings at alpine treeline. Plant Cell Env. 1999, 22, 407-415. [CrossRef]

37. Holtmeier, F.-K.; Broll, G. Layering in the Rocky Mountain treeline ecotone: Clonal conifer groups' distribution, structure, and functional role. Trees 2017, 31, 953-965. [CrossRef]

38. Cui, M.; Smith, W.K. Photosynthesis, water relations and mortality in Abies lasiocarpa seedling during natural establishment. Tree Physiol. 1991, 8, 37-46. [CrossRef] [PubMed]

39. Bockheim, J.G. Effects of Alpine and Subalpine Vegetation on Soil Development, Mt. Baker, Washington. Ph.D. Thesis, University of Washington, Washington, WA, USA, 1972.

40. Burns, R.M.; Honkala, B.H. Silvics of North America. Volume 1. Conifers; U.S. Department of Agriculture, Forest Service: Portland, OR, USA, 1990.

41. Heikkinen, O. Forest expansion in the subalpine zone during the past hundred years, Mount Baker, Washington U.S.A. Erkunde 1984, 38, 194-202. [CrossRef]

42. Grace, J. Impacts of Climate Change on the Tree Line. Ann. Bot. 2002, 90, 537-544. [CrossRef]

43. Holtmeier, F.K.; Broll, G.E. Treeline advance-Driving processes and adverse factors. Landsc. Online 2007, 1, 1-33. [CrossRef]

44. Dickerson-Lange, S.E.; Mitchell, R. Modeling the effects of climate change projections on streamflow in the Nooksack River basin, Northwest Washington: Effects of Climate Change on Streamflow in the Nooksack River Basin. Hydrol. Process. 2014, 28, 5236-5250. [CrossRef] 